\title{
Enhanced T-cell activation and differentiation in lymphocytes from transgenic mice expressing ubiquitination-resistant $2 \mathrm{KR}$
} LAT molecules

\author{
AB Rodriguez-Peña ${ }^{1,2,3}$, J Gomez-Rodriguez ${ }^{4}$, RL Kortum ${ }^{1,5}$, DC Palmer ${ }^{6}$, Z Yu $^{6}$, GC Guittard ${ }^{1}$, EA Wohlfert ${ }^{7,8,9}$, PB Silver ${ }^{10}$, JA Misplon ${ }^{11}$, \\ CL Sommers ${ }^{1}$, L Feigenbaum ${ }^{12}$, SL Epstein ${ }^{11}$, RR Caspi $^{10}{ }^{10}$ Y Belkaid ${ }^{7,8}$, NP Restifo ${ }^{6}$, LE Samelson ${ }^{1}$ and L Balagopalan $^{1}$
}

Linker for activation of T cells (LAT) is critical for the propagation of T-cell signals upon T-cell receptor (TCR) activation. Previous studies demonstrated that substitution of LAT lysines with arginines (2KR LAT) resulted in decreased LAT ubiquitination and elevated T-cell signaling, indicating that LAT ubiquitination is a molecular checkpoint for attenuation of T-cell signaling. To investigate the role of LAT ubiquitination in vivo, we have generated transgenic mice expressing WT and ubiquitin-defective $2 \mathrm{KR}$ LAT. On TCR stimulation of T cells from these mice, proximal signaling and cytokine production was elevated in $2 \mathrm{KR}$ versus wildtype (WT) LAT mice. Enhanced cytolytic activity as well as T-helper responses were observed on LAT expression, which were further elevated by 2KR LAT expression. Despite greater T-effector function, WT or 2KR LAT expression did not have any effect on clearance of certain pathogens or tumors. Our data support the model that lack of tumor clearance is due to increased differentiation and acquisition of effector phenotype that is associated with suboptimal immunity in an immunotherapy model. Thus, our data further reinforce the role of LAT ubiquitination in TCR signaling and uncovers a novel role for LAT in driving T-cell differentiation.

Gene Therapy (2015) 22, 781-792; doi:10.1038/gt.2015.48

\section{INTRODUCTION}

On antigen engagement, the T-cell antigen receptor (TCR) induces events leading to activation of $T$ cells and the various cellular changes essential to the onset of a productive immune response. The earliest events following TCR engagement include activation of protein tyrosine kinases. One critical protein tyrosine kinase substrate is the integral membrane adapter molecule linker for activation of T cells (LAT), which on phosphorylation, serves as a platform for the formation of protein complexes critical to TCR-mediated signaling reactions. Collectively, these protein complexes lead to the induction of multiple downstream pathways that direct almost all TCR-initiated cellular responses. $^{1,2}$

The outcome of TCR engagement is also influenced by signals from negative regulatory molecules that can inhibit T-cell function. Signal attenuation occurs at various stages during signal transduction. In addition to engagement of inhibitory receptors, dephosphorylation and assembly of complexes that trigger negative feedback loops, ubiquitination of proteins is a major way in which cells eliminate activated signaling molecules, thus attenuating signal transduction. ${ }^{3,4}$ Evidence accumulated over the past decade clearly indicates that protein ubiquitination is critically involved in the regulation of both innate and adaptive immune responses. ${ }^{5,6}$

We have demonstrated that the adapter LAT is subject to ubiquitination in T cells and have mapped the sites on which LAT is ubiquitinated. The expression of a mutated version of LAT resistant to ubiquitination (2KR LAT) caused elevated T-cell signaling at low doses of stimulation, indicating that LAT ubiquitination is a molecular checkpoint for attenuation of T-cell signaling and blocking LAT ubiquitination lowers the threshold for T-cell signaling. ${ }^{7}$ We hypothesized that enhanced signaling in cells expressing the ubiquitination-resistant form of LAT would augment immune responses to chronic infection and antitumor activity. Human T cells expressing 2KR LAT and a chimeric antigen receptor or an major histocompatibility complex class I-restricted TCR showed augmented function as assessed by enhanced cytokine secretion and cytotoxicity. ${ }^{8}$ These results indicate that disruption of LAT ubiquitination could be a promising strategy to augment T-cell function for adoptive antitumor immunotherapy.

Therapeutic targets for modulating immune responses are typically identified in vitro and then tested in animal models at a later stage in the evaluation process. However, to eliminate tumor, adoptively transferred $\mathrm{T}$ cells must proliferate extensively

\footnotetext{
${ }^{1}$ Laboratory of Cellular and Molecular Biology, Center for Cancer Research, National Cancer Institute, National Institutes of Health, Bethesda, MD, USA; ${ }^{2}$ Centro de Investigación del Cáncer, Salamanca, Spain; ${ }^{3}$ Instituto de Biología Molecular y Celular del Cáncer, Consejo Superior de Investigaciones Científicas-University of Salamanca, Salamanca, Spain; ${ }^{4}$ Cell Signaling and Immunity Section, National Human Genome Research Institute, National Institutes of Health, Bethesda, MD, USA; ${ }^{5}$ Department of Pharmacology; Uniformed Services University of the Health Sciences, Bethesda, MD, USA; ${ }^{6}$ Tumor Immunology Section, Center for Cancer Research, National Cancer Institute, National Institutes of Health, Bethesda, MD, USA; ${ }^{7}$ Immunity at Barrier Sites Initiative, Laboratory of Parasitic Diseases, National Institute of Allergy and Infectious Disease, National Institutes of Health, Bethesda, MD, USA; ${ }^{8}$ Mucosal Immunology Section, Laboratory of Parasitic Diseases, National Institute of Allergy and Infectious Disease, National Institutes of Health, Bethesda, MD, USA; ${ }^{9}$ Department of Microbiology and Immunology, School of Medicine and Biomedical Sciences, University at Buffalo (SUNY), Buffalo, NY, USA; ${ }^{10}$ Immunoregulation Section, National Eye Institute, National Institutes of Health, Bethesda, MD, USA; ${ }^{11}$ Center for Biologics Evaluation \& Research, Food and Drug Administration, Silver Spring, MD, USA and ${ }^{12}$ Laboratory Animal Sciences Program, Leidos Biomedical Research Inc, Frederick National Laboratory for Cancer Research, Frederick, MD, USA. Correspondence: Dr L Balagopalan, Laboratory of Cellular and Molecular Biology, Center for Cancer Research, National Cancer Institute, National Institutes of Health, Bldg. 37, Rm, 2064, Bethesda, MD 20892, USA.

E-mail: balagopl@mail.nih.gov

Received 24 September 2014; revised 22 February 2015; accepted 20 March 2015; accepted article preview online 27 May 2015 ; advance online publication, 18 June 2015
} 
in vivo, traffic to the tumor and retain function in the immunosuppressive tumor microenvironment, all steps that can only be tested in in vivo tumor models. Therefore, to investigate the role of LAT ubiquitination in vivo, we have generated transgenic mice expressing wild-type (WT) and ubiquitin-defective 2KR LAT in postthymic mature T cells. We observed that consistent with studies in cell lines, murine $T$ cells expressing 2KR LAT displayed enhanced TCR-dependent proximal signaling, cytokine production and proliferation. Furthermore, enhanced T-helper cell function and cytolytic function were observed. Surprisingly however, when challenged to clear a pathogen or tumor, expression of WT or 2KR LAT was not beneficial. Evaluation of activation markers revealed that expression of WT or 2KR LAT induced a more differentiated effector phenotype that is associated with suboptimal immune function in an immunotherapy model. Our data further bolster the role of LAT ubiquitination as a molecular checkpoint in TCR signaling and uncovers a novel role for LAT in driving T-cell differentiation. Furthermore, we emphasize that in vivo studies of a given genetic modifier of an immune response and how it affects immunotherapy are warranted early in the testing process, as enhanced in vitro activity of $\mathrm{T}$ cells is an inadequate predictor of increased in vivo efficacy.

\section{RESULTS}

Generation and phenotypic characterization of LAT transgenic mice

Transgenic mice expressing WT LAT and ubiquitin-defective 2KR LAT under the control of the distal Lck promoter were generated to define the role of LAT ubiquitination in postthymic, mature $\mathrm{T}$ cells in vivo (Supplementary Figure S1a). We confirmed that mutation of lysines greatly diminished ubiquitination of murine LAT, similar to the effect of the 2KR LAT mutation in human LAT (Supplementary Figure $S 1 b^{7}$ ). We had previously shown that exogenous expression of $2 \mathrm{KR}$ LAT enhances proximal TCR signaling to a greater extent than expression of WT LAT. ${ }^{7,8}$ The levels of TCR signaling are intrinsically linked to intrathymic T-cell development, and alterations in signaling can shift the balance between positive and negative selection, thereby altering the pool of mature T cells. ${ }^{9}$ To avoid any differences in development that expression of a 2 KR LAT transgene might cause, transgenic mice were generated using the distal Lck promoter, which promotes transgene expression after positive and negative selection are completed. ${ }^{10}$ Founder lines showing LAT transgene expression closest to endogenous (endo) LAT levels in C57BL/6 mice were chosen for further study (Supplementary Figure S1c). Assessment of transgene expression using hemaglutinin staining revealed that both WT and 2KR LAT transgenes were expressed once positive and negative selection were complete, thus showing staining predominantly in CD4 single-positive and CD8 single-positive thymocytes and $\mathrm{CD}^{+}$and $\mathrm{CD}^{+}$peripheral $\mathrm{T}$ cells, but not in double-positive thymocytes, as would be expected with the distal Lck promoter (Supplementary Figure S1d). We confirmed transgene expression by PCR for the transgenic lines that were chosen (Supplementary Figure S1e). Assessment of LAT staining by flow cytometry in T cells of WT and 2KR founder lines correlated well with levels of LAT expression evaluated by western blotting (compare Supplementary Figure S1c and S1f). Total LAT expression (sum of transgenic and endogenous LAT) were, respectively, $1.3 \times$ for WT LAT $(1.1 \times$ transgenic $+0.2 \times$ endogenous $)$ and $1.7 \times$ for 2 KR LAT $(1.3 \times$ transgenic $+0.4 \times$ endogenous) that of endogenous LAT expression in transgene-negative $\left(\mathrm{TG}^{-}\right)$mice.

To confirm that transgene expression did not alter thymocyte development, WT and 2KR transgenic thymoyctes were isolated and assessed for various cell surface markers that change during development. Assessment of CD4 and CD8 staining revealed that the populations of double-positive and single-positive thymoyctes were not altered. Furthermore, assessment of CD69, TCR $\beta$, CD24 and $C D 3 \varepsilon$ revealed that positive selection was normal in these mice (Supplementary Figure S2a). ${ }^{11}$ Cellularity (data not shown) and frequency of $\mathrm{CD}^{+}$and $\mathrm{CD} 8^{+} \mathrm{T}$ cells in both lymph nodes (LN) and spleens were also normal (Supplementary Figure S2b). Similar numbers and percentages of regulatory $T$ cells $\left(T_{\text {regs }}\right)$ in thymus and LN were also observed, indicating that transgene expression does not alter $\mathrm{T}_{\text {reg }}$ selection (Supplementary Figure S2c).

Proximal T-cell signaling is enhanced in lymphocytes expressing 2KR LAT

We have previously shown that cells expressing ubiquitinresistant LAT display enhanced signaling in human cell lines and primary human $T$ cells., ${ }^{78}$ To assess the overall activation of signaling components downstream of the TCR in LAT-expressing transgenic murine T cells, western blot analysis was performed on lysates of purified $\mathrm{CD}^{+}$and $\mathrm{CD}^{+}{ }^{+}$cells from LN cells. Using phospho-specific antibodies, we found that whereas activation of the upstream kinase ZAP-70 was similar in WT and 2KR LAT cells, there was a prominent increase in the levels of phosphorylated LAT in $2 \mathrm{KR}$ LAT-expressing $\mathrm{CD}^{+}$and $\mathrm{CD}^{+}{ }^{+} \mathrm{T}$ cells (Figures $1 \mathrm{a}$ and $\mathrm{b}$ ). Comparison of phosphorylated LAT levels in $\mathrm{TG}^{-}, \mathrm{WT}$ and $2 \mathrm{KR}$ LAT-expressing $\mathrm{CD}^{+}{ }^{+} \mathrm{T}$ cells revealed that while the level of phosphorylated LAT in 2KR LAT cells was clearly the highest of the three groups, total phosphorylated LAT levels (reflecting the sum of transgenic and endogenous pLAT) was higher in WT LAT-expressing cells than in $\mathrm{TG}^{-}$cells (Supplementary Figure S3). Downstream of LAT, phosphorylation patterns of signaling proteins diverged in $\mathrm{CD}^{+}$versus $\mathrm{CD}^{+} \mathrm{T}$ cells. Whereas the abundance of phosphorylated PLC $-\gamma 1$ and extracellular-signal-regulated kinase (ERK) were greater in CD4 ${ }^{+}$2KR LAT cells, CD8 ${ }^{+}$cells did not exhibit these differences. Phospho-ERK as assessed by flow cytometry by gating on $\mathrm{CD}^{+}$or $\mathrm{CD}^{+}$cells produced similar results (Supplementary Figure S4). Tyrosine phosphorylation of PLC $-\gamma 1$ results in its activation and generation of second messengers, yielding rises in free cytosolic calcium. The elevated phosphorylation of PLC $-\gamma 1$ in $C D 4^{+}$cells suggested that calcium signaling might be augmented in cells expressing 2KR LAT. To test this notion, we measured calcium flux in single cells after stimulation with soluble anti-CD3r and anti-CD28 antibodies. Consistent with western blotting results, $C D 4^{+}$cells expressing $2 \mathrm{KR}$ LAT had an augmented peak calcium signal compared with cells expressing WT LAT. Surprisingly, CD8 ${ }^{+} \mathrm{T}$ cells expressing $2 \mathrm{KR}$ LAT also displayed enhanced calcium flux (Figure 1c), even though PLC- $\gamma 1$ phosphorylation was unaltered. Overall, these data demonstrate that proximal T-cell signaling is enhanced in lymphocytes expressing 2KR LAT compared with WT LAT.

2KR LAT expression enhances TCR-stimulated cytokine production and proliferation

To determine whether the enhanced early TCR signaling observed in 2KR LAT transgenic T cells also extended to later phase T-cell responses, cytokine production at $72 \mathrm{~h}$ post activation was evaluated. Sorted naive $\mathrm{CD}^{+}$or $\mathrm{CD}^{+}$cells from $\mathrm{TG}^{-}, \mathrm{WT}$ and 2KR LAT mice were stimulated for $72 \mathrm{~h}$ to examine their ability to produce interferon (IFN)- $\gamma$, tumor necrosis factor- $\alpha$ and interleukin (IL)-2. The percentage of WT LAT CD4 ${ }^{+}$-expressing cells that produced these cytokines were higher than $\mathrm{TG}^{-}$controls $(1.3-1.4 \times)$, but much larger increases were observed in $2 \mathrm{KR}$ LAT cells (4-6x; Figure 2a). These differences were less pronounced in $\mathrm{CD}^{+}$cells, where the percentage of cytokineexpressing cells increased 1.1-1.6 fold in 2KR LAT cells compared with WT LAT controls (Figure 2b). Notably, expression of 2KR LAT increased the median fluorescence intensity (data not shown) as 
a
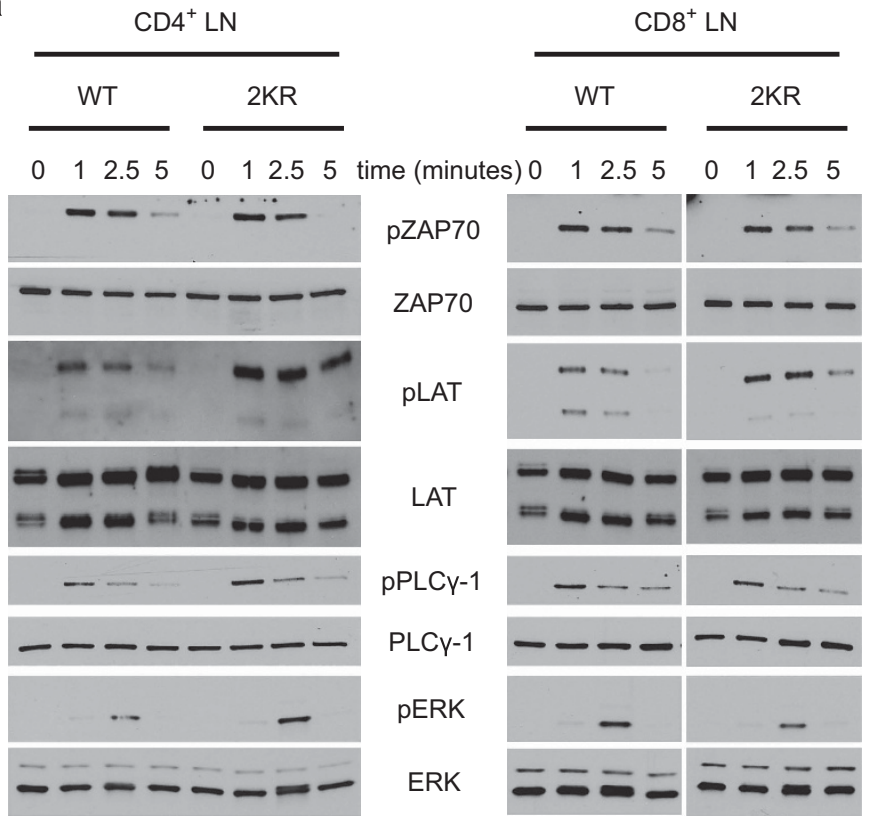

b
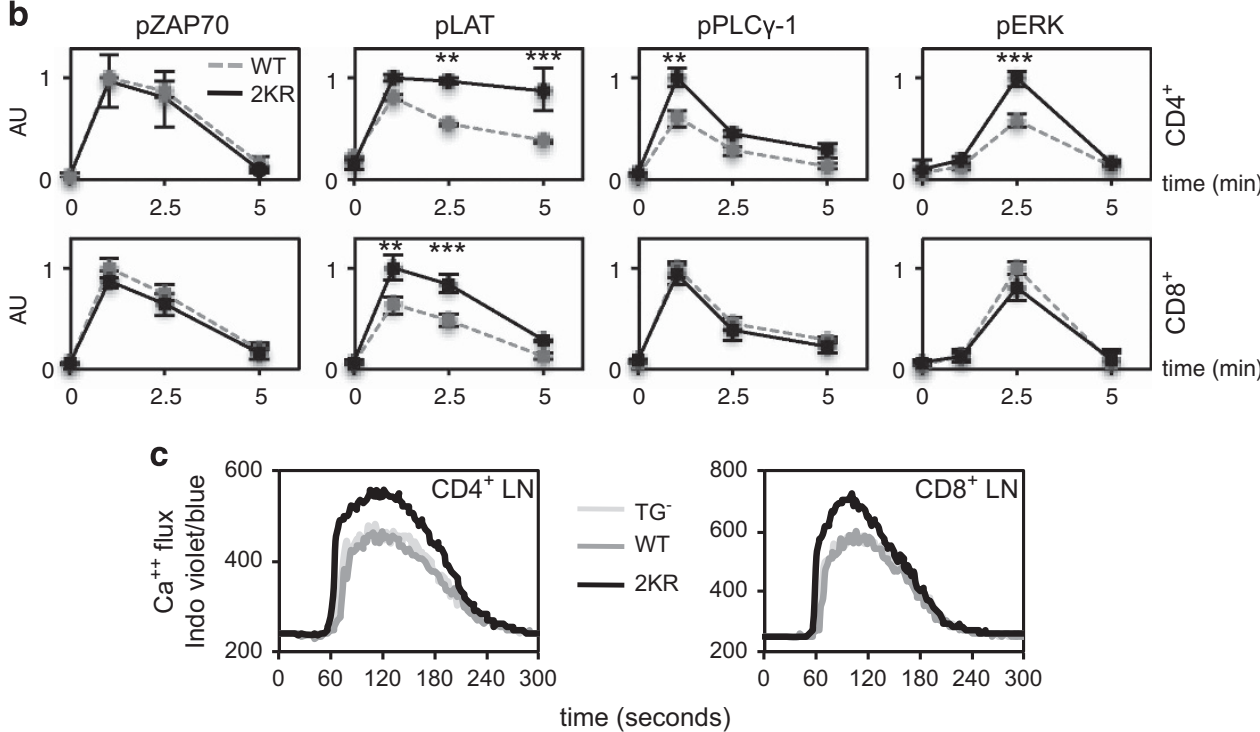

Figure 1. T-cell signaling is enhanced in cells expressing ubiquitin-resistant 2KR LAT. (a) Western blotting for pZAP70, ZAP70, pLAT (Tyr191), LAT, pPLC- $\gamma 1$ (Tyr783), PLC- $\gamma 1$, pERK1/2 and ERK1/2 in whole-cell lysates from purified CD4 ${ }^{+}$or CD8 ${ }^{+}$lymph node (LN) T cells from WT or 2 KR LAT transgenic mice stimulated with $3 \mu \mathrm{g} \mathrm{ml}^{-1} \alpha-C D 3 \varepsilon+10 \mu \mathrm{g} \mathrm{ml}^{-1} \alpha-C D 28$ antibodies for the indicated time. (b) Quantitation of the abundances of pZAP70, pLAT, pPLC- $\gamma 1$ and pERK proteins relative to those of the corresponding total proteins from the experiments represented in (a). Data are means \pm s.e.m. AU, arbitrary units. ${ }^{* *} P \leqslant 0.01,{ }^{* * *} P \leqslant 0.001$. (c) Representative time-dependent calcium flux (indoviolet/indo-blue) in gated CD4 ${ }^{+}$or $\mathrm{CD}^{+}$LN T cells from TG ${ }^{-}$, WT and $2 \mathrm{KR}$ LAT mice, stimulated with $3 \mu \mathrm{g} \mathrm{ml}{ }^{-1} \alpha-\mathrm{CD}_{2} \varepsilon^{+} 5 \mu \mathrm{g} \mathrm{ml}{ }^{-1} \alpha-\mathrm{CD}_{2} 8$ antibodies for the indicated time.

well as the percentage of cytokine-producing cells, indicating that TCR stimulation induced higher cytokine levels on a per-cell basis.

The requirement for LAT ubiquitination in mediating TCRinduced T-cell proliferation was also examined. Purified $\mathrm{CD}^{+}$and $\mathrm{CD}^{+}{ }^{+}$cells from $\mathrm{TG}^{-}$, WT and $2 \mathrm{KR}$ LAT transgenic mice were stimulated with varying concentrations of anti-CD3E in the absence or presence of anti-CD28. Low concentrations of antiCD3ع $\left(0.1\right.$ and $\left.0.5 \mu \mathrm{g} \mathrm{ml}^{-1}\right)$ were sufficient to induce proliferation in $\mathrm{CD}^{+} \mathrm{T}$ cells from $2 \mathrm{KR}$ LAT-expressing transgenic mice but had little effect on $\mathrm{CD}^{+}{ }^{+} \mathrm{T}$ cells from WT LAT transgenic mice or $\mathrm{TG}^{-}$ mice (Figure 2c). In contrast, no differences in proliferation were observed in $\mathrm{CD}^{+} \mathrm{T}$ cells from all mice at the antibody concentrations tested (Figure 2d).
The cytokine production and proliferation data show that $2 \mathrm{KR}$ LAT-expressing $\mathrm{CD}^{+}$and $\mathrm{CD}^{+}{ }^{+}$cells display enhanced cytokine production, with $\mathrm{CD}^{+}$cells displaying more pronounced increases when LAT ubiquitylation is abolished. Moreover, CD4 ${ }^{+}$ 2KR LAT-expressing T cells are more sensitive to low doses of stimulation, indicating that LAT ubiquitination sets the threshold for T-cell stimulation. Thus, signals regulating cytokine production and proliferation of mature $\mathrm{CD} 4^{+}$and $\mathrm{CD} 8^{+} T$ cells are differentially sensitive to the strength of the signal emanating from the LAT signaling complexes, with $\mathrm{CD}^{+}$cells being more sensitive. Notably, cells expressing 2KR LAT do not show spontaneous proliferation (Figures 2c and d) or constitutive cytokine secretion (data not shown). 
a

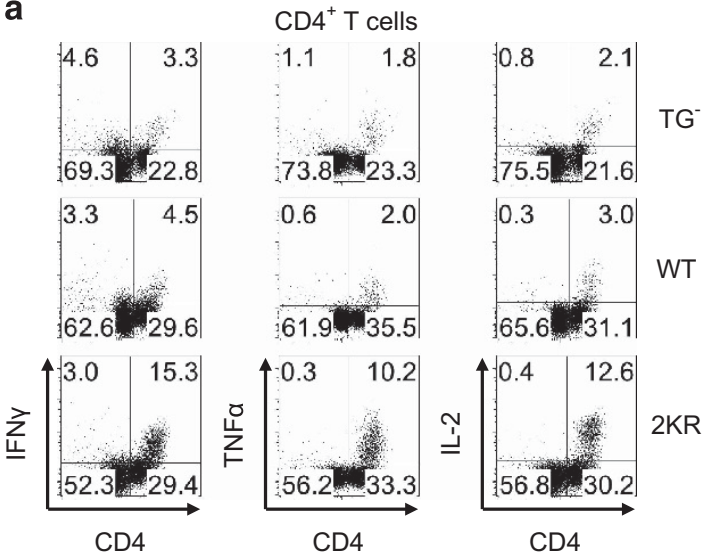

C

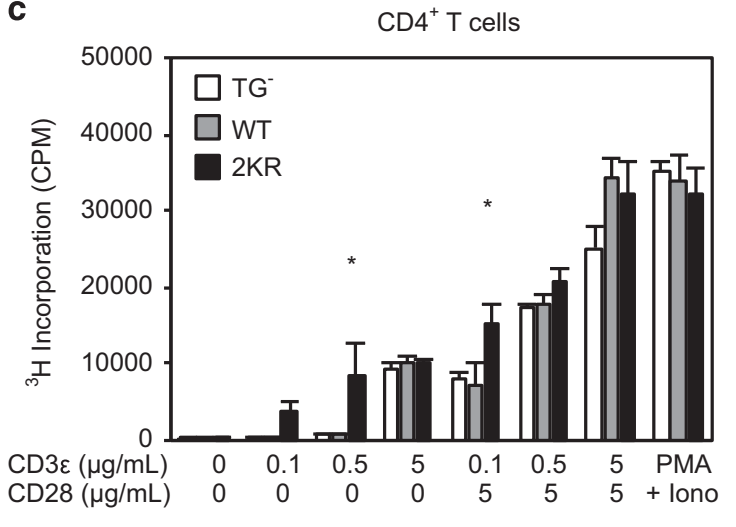

b

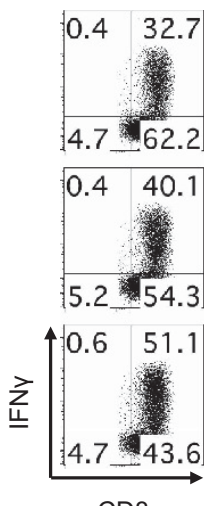

$\mathrm{CD}^{+} \mathrm{T}$ cells
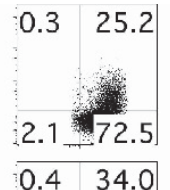

0.434 .0

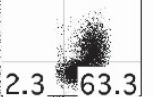

$2.3 \times 63.3$

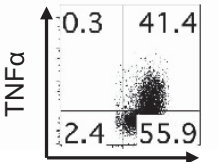

CD8
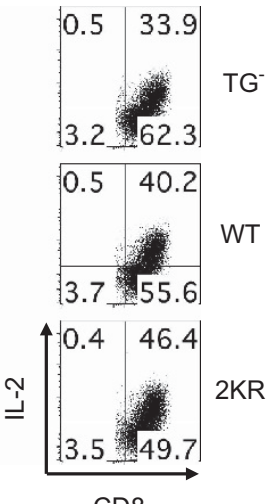

d

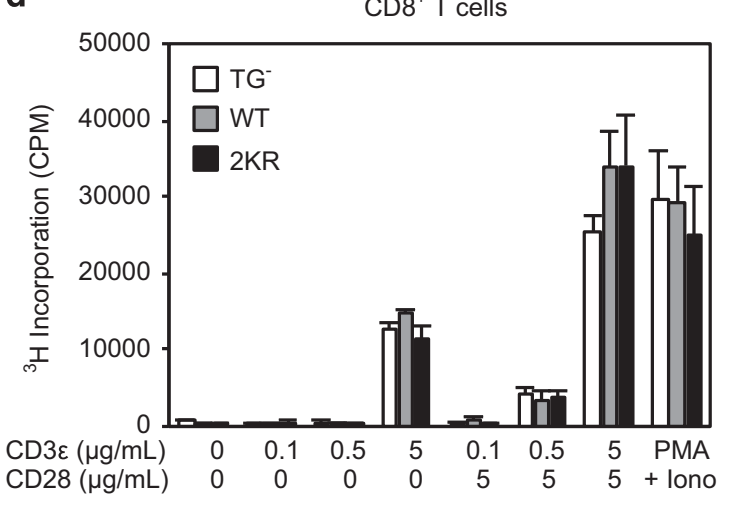

Figure 2. Enhanced cytokine production and proliferation in cells expressing ubiquitin-resistant 2KR LAT. (a and b) Flow cytometry dot plots of $\mathrm{CD}^{+} \mathrm{T}$ lymphocytes stimulated with anti-CD3ع/CD28 antibodies in the presence of APCs (a) or CD8 ${ }^{+} \mathrm{T}$ lymphocytes stimulated with platebound anti-CD3ع/CD28 antibodies (b) for $72 \mathrm{~h}$, and stained with the indicated antibodies to assess cytokine production. Three independent experiments were performed and data are presented from one representative experiment. (c and d) Sorted naive CD4 ${ }^{+}(\mathbf{c})$ or CD8 ${ }^{+}(\mathbf{d}) \mathrm{T}_{\mathrm{cell}} \mathrm{s}$ were stimulated with anti-CD3E/CD28 plate-bound antibodies at the indicated concentrations and pulsed with ${ }^{3} \mathrm{H}$-thymidine for $16 \mathrm{~h}$ before being harvested. PMA/ionomycin-incubated T lymphocytes were used as a positive control for proliferation. Data presented are averages plus s.e.m. ${ }^{*} P \leqslant 0.05$.

LAT expression enhances in vitro lytic activity of cytotoxic T cells To study the role of $2 \mathrm{KR}$ LAT in $\mathrm{CD} 8^{+} \mathrm{T}$-cell cytolytic activity, either WT or 2KR LAT mice were crossed with OT-I TCR transgenic mice expressing a clonal TCR recognizing the ovalbumin peptide SIINFEKL $\left(\mathrm{OVA}_{257-264}\right)$ in the context of $\mathrm{H}-2 \mathrm{~K}^{\mathrm{b}} .^{12}$ This system allowed us to compare the differential killing ability of WT and 2KR LAT OT-I cytotoxic T cells (CTLs) on target cells under defined antigen conditions. As demonstrated by the in vitro CTL assay, expression of either WT or 2KR LAT in activated OT-I CTLs enabled higher levels of cytotoxicity against $\mathrm{OVA}_{257-264}$ peptide-pulsedEL4 thymoma target cells compared with OT-I CTLs, with 2KR LAT transgenic CTLs showing the highest ability to kill targets (Figure 3a). In addition, intracellular expression of IFN- $\gamma$ and granzyme B (GzmB), the granule serine protease involved in apoptotic processes during target cell-mediated cytolysis, were examined in activated CTLs. Consistent with the lytic activity described above, expression of WT and 2KR LAT caused elevated percentages of cells producing IFN- $\gamma$ and GzmB (Figure 3b). Furthermore, the levels of IFN- $\gamma$ and $\mathrm{GzmB}$ as measured by median fluorescence intensity were greater in WT LAT-expressing cells than $\mathrm{OT}-\mathrm{I}^{+}$control cells, and highest in 2KR LAT-expressing cells (Figure $3 \mathrm{c}$ ). These results indicate that LAT is a limiting component of the signaling pathway that mediates the lytic response of mature CTLs to antigen.
2KR LAT expression enhances T-dependent immune responses To evaluate primary humoral responses mediated by T-cell interaction with B cells, antibody production and germinal center (GC) B-cell development were determined in the serum and spleens of TG ${ }^{-}$, WT LAT and 2KR LAT transgenic mice immunized with the T-cell-dependent antigen 4-hydroxy-3-nitrophenylacetyl hapten conjugated to Keyhole Limpet Hemocyanin (NP)-KLH. Sera of immunized vs non-immunized mice showed increased levels of NP-specific immunoglobulin G (IgG) isotypes detected by enzymelinked immunosorbent assay (ELISA) 14 days post immunization. Furthermore, 2KR LAT mice exhibited a markedly increased production of $\mathrm{IgG}_{1}$ levels in comparison with $\mathrm{TG}^{-}$and WT LAT animals (Figure 4a). Similar levels of NP-specific $\operatorname{lgG}_{2 b}$ and $\operatorname{lgG}_{3}$ were detected in all immunized groups (Supplementary Figure $\mathrm{S} 5 \mathrm{a}$ and b). The NP-lipopolysaccharide antigen, which elicits a T-independent response, was additionally tested to examine primary humoral responses in mice. NP-specific $\lg _{3}$ titers were measured in serum and no differences in antibody levels were found among mouse groups 20 days following T-independent immunization (Supplementary Figure S5c).

After immunization, B cells downregulate immunoglobulin $D$ and express activation markers including Fas. A small fraction of precursor B cells within the follicles upregulate differentiation markers including GL-7 and undergo a rapid clonal expansion, 


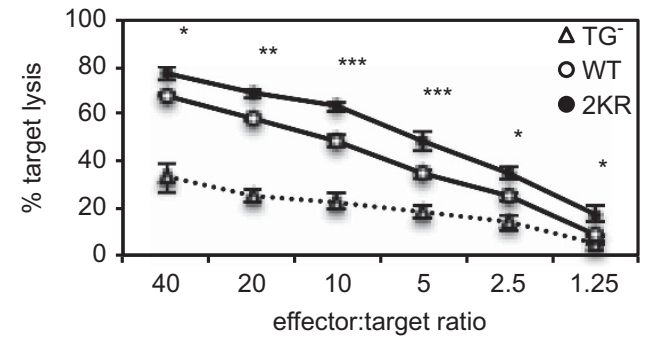

b

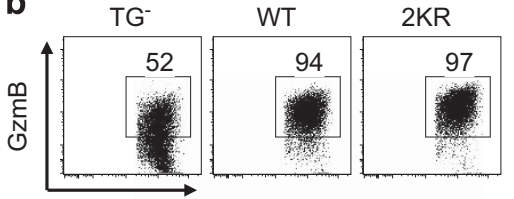

CD8

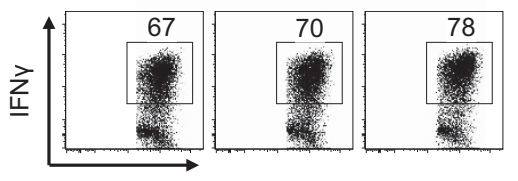

CD8

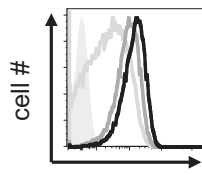

GzmB

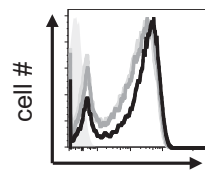

IFNY

\begin{tabular}{|c|c|c|}
\hline & MFI GzmB & MFI IFNy \\
\hline TG $^{-}$ & 432 & 596 \\
\hline WT & 753 & 697 \\
\hline 2KR & 1185 & 1114 \\
\hline
\end{tabular}

Figure 3. 2KR LAT OT-I cytotoxic T cells display an enhanced in vitro lytic activity in T-cell targets. (a) Cytolysis of $30 \mathrm{~nm}$ OVA peptide-pulsed-EL4 cells after $4 \mathrm{~h}$ of incubation with 6-day-activated OT-I (TG), WT LAT OT-I (WT) and 2KR LAT OT-I (2KR) CD8 ${ }^{+}$splenocytes. Graph shows the average cytotoxicity from duplicate wells \pm s.e.m. for varying effector to target ratios of three independent experiments. (b) Intracellular granzyme B (GzmB) expression and intracellular IFN- $\gamma$ production by 6day-activated OT-I (TG ${ }^{-}$), WT LAT OT-I (WT) and 2KR LAT OT-I (2KR) CTLS detected by flow cytometry. Data are representative of two independent experiments. (c) Numbers indicate median fluorescence intensity (MFI) of GzmB and IFN- $\gamma$ in 6-day-activated OT-I (TG ${ }^{-}$), WT LAT OT-I (WT) and 2KR LAT OT-I (2KR) CTLs measured by flow cytometry. Data are representative of two independent experiments. ${ }^{*} P \leqslant 0.05,{ }^{*} P \leqslant 0.01,{ }^{* * *} P \leqslant 0.001$.

forming GCs. ${ }^{13}$ Thus, the humoral response can be evaluated by staining for GCs using anti-Fas and anti-GL-7. Consistent with the antibody responses described above, transgenic mice expressing either WT or 2KR LAT exhibited enhanced GC formation compared with $\mathrm{TG}^{-}$controls, with the highest increase found for $2 \mathrm{KR}$ LAT immunized mice (Figures $4 \mathrm{~b}$ and $\mathrm{c}$ ).

Testing for T-cell influences on B-cell responses in our transgenic model, we have found that mice with T cells expressing transgenic WT or 2KR LAT induce a higher differentiation of B cells into GCs, whereas 2KR LAT expression differentially upregulates the levels of $\mathrm{IgG}_{1}$ antibodies produced by the $B$ cells in response to a defined antigen. Taking all these data together, we provide evidence that 2KR LAT mice display more potent humoral immunity than WT LAT or $\mathrm{TG}^{-}$mice.

Evaluation of effectiveness of increased signaling in 2KR LAT-expressing $\mathrm{T}$ cells in in vivo models of disease

Based on the marked influence of 2KR LAT expression on proximal T-cell signaling, cytokine expression, proliferation, CTL activity and a
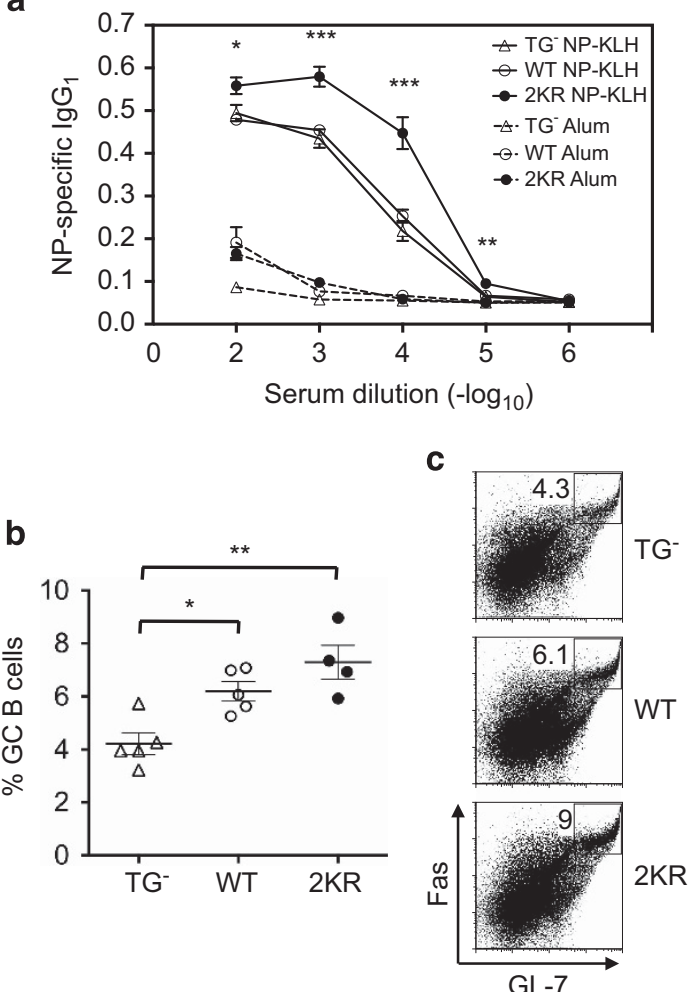

Figure 4. 2KR LAT transgenic mice exhibit enhanced germinal center responses. (a) Production of NP-specific $\lg _{1}$ antibodies 14 days after immunization with NP-KLH measured by ELISA (OD at $405 \mathrm{~nm}$ ) in transgenic negative $\left(\mathrm{TG}^{-}\right)$, WT and $2 \mathrm{KR}$ LAT mice. Serial dilutions of serum: $2-6=10^{-2}-10^{-6} . n=3-5$ mice per group. Dotted and solid lines represent non-immunized (Alum adjuvant) and immunized mice (Alum adjuvant/NP-KLH), respectively. (b) Percentage of germinal center (GC) B cells (B220 ${ }^{+} \mathrm{IgD}^{\mathrm{lo}} \mathrm{GL}^{-} 7^{\text {hi }} \mathrm{Fas}^{\text {hi }}$ ) detected in spleens 7 days post immunization with the T-dependent antigen NP-KLH. (c) Representative image of GC formation evaluated in splenic cells by gating on $\mathrm{B}^{2} 2 \mathrm{O}^{+} \mathrm{IgD} \mathrm{D}^{\mathrm{lo}} 7$ days after T-dependent (NP-KLH in Alum) immunization. ${ }^{*} P \leqslant 0.05,{ }^{* *} P \leqslant 0.01,{ }^{* *} P \leqslant 0.001$.

in vivo B-cell responses, we tested whether $2 \mathrm{KR}$ LAT transgenic mice responded more efficiently to pathogenic challenges in a variety of in vivo disease models. We first investigated the role of LAT ubiquitination in vivo in the influenza model because T cells are known to have a role in clearance of influenza virus infection. ${ }^{14}$ $\mathrm{TG}^{-}$, WT and 2KR LAT transgenic mice were infected with influenza virus (H1N1 subtype). Mice were followed for weight loss and survival for 15 days. No significant differences in weight loss or mortality were observed between the three groups (Figure 5a and Supplementary Figure S6a).

To evaluate the importance of LAT ubiquitination in immune protection against intracellular pathogens, resistance of transgenic mice to Toxoplasma gondii was examined. In this model, both $\mathrm{CD}^{+}$and $\mathrm{CD}^{+}$cells are important for controlling infection. ${ }^{15}$ Infection with a low dose of T. gondii resulted in $100 \%$ survival. A highly CTL-polarized immune response was observed in the mesenteric lymph nodes of 2KR LAT mice orally infected with a low dose of $T$. gondii, as demonstrated by higher frequency of activated and proliferating $C D 8^{+}$population producing IFN- $\gamma$ and tumor necrosis factor-a (Supplementary Figure S6b and d) when compared with WT LAT mice. However, serum hepatic enzymes (data not shown) and parasite burden (Figure 5b) 9 days post infection were not significantly different in WT and 2KR LATexpressing mice, indicating that expression of ubiquitin-resistant mutant LAT did not provide increased protection against the pathogen. 

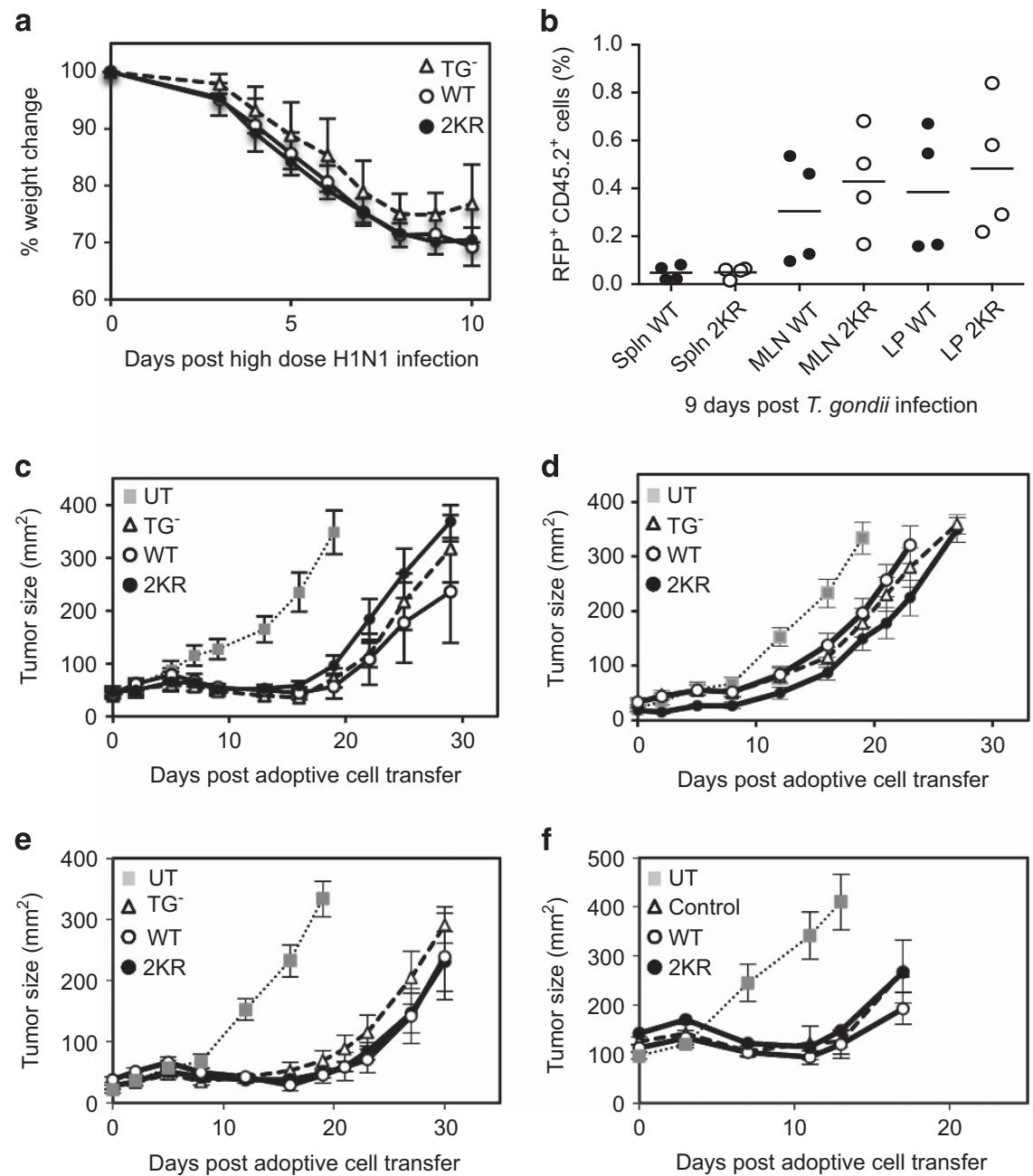

Figure 5. In vivo models to test enhanced function of 2KR LAT-expressing T cells. (a) Morbidity in transgene-negative (TG'), WT or 2KR LATexpressing mice after challenge with mouse-adapted influenza virus. The body weights of individual mice are shown only through day 10 , but were measured through day 15 by which time all surviving animals were regaining their initial weight. The values are the means of five mice in each group. (b) T. gondii parasite burden measured as percentage of red fluorescent protein positive cells (RFP ${ }^{+}$) detected in CD45.2 ${ }^{+}$cells of spleen (Spln), mesenteric lymph nodes (MLN) and lamina propria (LP) compartments of WT LAT and 2KR LAT mice. (c) Growth of B16/OVA melanoma after no treatment (UT), or adoptive transfer of OT-I (TG) or WT LAT OT-I (WT) or 2KR LAT OT-I (2KR) CD8 ${ }^{+}$T cells (10 ${ }^{6}$ cells transferred, $n=5$ ). (d) Growth of B16 melanoma after no treatment (UT) or adoptive immunotherapy of TG ${ }^{-}$or WT LAT (WT) or 2KR LAT (2KR) $\mathrm{CD}^{+}$T cells transduced with pmel-1-TCR $\left(10^{6}\right.$ cells transferred, $\left.n=5\right)$. (e) Growth of B16/OVA melanoma after no treatment (UT), or adoptive transfer of isolated naive (CD8 $\left.{ }^{+} \mathrm{CD}_{2} \mathrm{~L}^{+} \mathrm{CD} 44^{-}\right)$OT-I (TG ${ }^{-}$) or WT LAT OT-I (WT) or 2KR LAT OT-I (2KR) T cells $\left(10^{6}\right.$ cells transferred, $\left.n=5\right)$. (f) Naive isolated splenocytes $\left(\mathrm{CD} 8^{+} \mathrm{CD} 62 \mathrm{~L}^{+} \mathrm{CD} 44^{-}\right)$from pmel-1 transgenic mice were isolated, activated with anti-CD3 and transduced with retrovirus expressing Thy1.1 only (Control) or Thy 1.1 in combination with WT LAT (WT) or 2KR LAT (2KR). Transduced cells were injected into tumorbearing mice $\left(10^{6}\right.$ cells transferred, $\left.n=5\right)$. Results shown as means \pm s.e.m.

We also interrogated the effect of interruption of LAT ubiquitination on autoimmunity. We used two different models of T-cell based autoimmune diseases: Experimental Autoimmune Encephalomyelitis, (the murine model for multiple sclerosis ${ }^{16}$ ) and Experimental Autoimmune Uveoretinitis (a model for autoimmune uveitis ${ }^{17}$ ). Both models are mediated by antigen-specific CD4 ${ }^{+}$ T cells and share many essential effector mechanisms, but affect different organs. Notably, both WT LAT and 2KR LAT-expressing transgenic mice exhibited similar clinical Experimental Autoimmune Encephalomyelitis and Experimental Autoimmune Uveoretinitis scores (Supplementary Figure S6e and f).

In light of the effect of 2KR LAT expression on proximal T-cell signaling, cytokine production and proliferation, CTL activity and in vivo $\mathrm{B}$-cell responses, the lack of any increase in functionality of 2KR LAT-expressing $\mathrm{T}$ cells to protect against disease was unexpected. To evaluate whether lack of increase in functionality was due to increased suppressive potency of $2 \mathrm{KR} \mathrm{T}_{\text {regs, }}$ suppression of effector cell proliferation by $\mathrm{TG}^{-}, \mathrm{WT}$ and $2 \mathrm{KR} \mathrm{T}_{\text {regs }}$ was evaluated. $T_{\text {regs }}$ from all three mice were equally capable of suppressing proliferation of responder $T$ cells at the various coculturing ratios tested (Supplementary Figure S7), indicating that WT or 2KR LAT expression does not affect $\mathrm{T}_{\text {reg }}$ suppressive potency.

\section{Effect of LAT expression on tumor immunity}

Enhanced cytolytic activity in CTLs expressing 2KR LAT prompted us to examine whether WT or 2KR LAT expression in CTLs could augment antitumor activity. We first tested this in a therapeutic model of B16-OVA melanoma, where mice were injected subcutaneously with B16-OVA melanoma cells. B16-OVA melanoma cells express the surrogate tumor antigen chicken ovalbumin (OVA) in the context of the $\mathrm{H}-2 \mathrm{~K}^{\mathrm{b}}$ major histocompatibility complex I molecule. OVA is recognized by $\mathrm{CD}^{+} \mathrm{T}$ cells from OT-I TCR transgenic mice. ${ }^{12}$ When tumors reached a size of $5 \mathrm{~mm}^{2}$, mice were injected with OT-I, WT LAT OT-I or 2KR LAT OT-I 
expressing $\mathrm{CD}^{+} \mathrm{T}$ cells. Following transfer, tumor size was monitored in all experimental groups. Tumor growth was rapid in untreated mice. Though adoptive transfer of $T$ cells delayed tumor growth as compared with untreated controls as expected, no significant differences were observed between TG $^{-}$, WT LAT and $2 \mathrm{KR}$ LAT-expressing cells, indicating that enhanced LAT expression was insufficient to suppress tumor development (Figure 5c). Antitumor activity was also tested in a pmel-1 mouse model, in which $T$ cells recognize mgp100, an endogenous melanoma antigen. ${ }^{18,19}$ Again, no significant differences in tumor regression were observed between the three groups of transferred cells (Figure $5 \mathrm{~d}$ ). Emerging data from mouse studies as well as human clinical trials support the hypothesis that lessdifferentiated $\mathrm{T}$ cells are more therapeutically effective on adoptive transfer. ${ }^{20}$ To uncouple the differentiation state of adoptively transferred $\mathrm{CD} 8^{+} \mathrm{T}$ cells from their ability to mediate tumor regression, two additional adoptive transfer experiments were performed. In the first experiment, naive $\mathrm{CD}^{+}$cells were isolated from $\mathrm{TG}^{-}, \mathrm{WT}$ and $2 \mathrm{KR}-\mathrm{OT}-\mathrm{I}$ transgenic mice and their ability to clear subcutaneous B16-OVA melanomas was evaluated. No significant differences were observed between TG ${ }^{-}$, WT LAT and 2KR LAT-expressing cells, The second approach involved gene transfer, which in addition to being an effective method to redirect $T$ cells toward tumor antigens also provides a means for enhancing T-cell function. In this experiment, naive $\mathrm{CD}^{+} \mathrm{T}$ cells were isolated from pmel-1 transgenic mice and transduced with control, WT or 2KR LAT-expressing retroviruses. Transduced cells were injected into tumor-bearing mice and tumor clearance was evaluated over a 17-day period. No significant differences in tumor regression were observed between the three groups of transferred cells in either experiment (Figures $5 e$ and f).

\section{Acquisition of effector phenotype caused by LAT expression}

In terms of efficacy in adoptive immunotherapy for cancer, naive $T$ cells have been shown to be more effective than memory $T$ cells $^{21-23}$ and central memory cells are more effective than effector memory cells. ${ }^{24}$ These findings have led to the hypothesis that the differentiation state of $\mathrm{CD}^{+} \mathrm{T}$ cells is inversely related to their capacity to proliferate and persist. ${ }^{25,26}$ To determine whether the lack of enhanced T-cell responses by 2KR LAT-expressing $T$ cells reflected decreased functionality of these cells as a result of increased differentiation, CD44 and CD62L expression was evaluated. Expression of WT or 2KR LAT caused a significant reduction in the percentage of naive $T$ cells $\left(C D 44^{\text {low }}, C D 62 L^{\text {high }}\right)$ and expansion of central memory cells (CD44 ${ }^{\text {high }}, \mathrm{CD}_{2} \mathrm{~L}^{\text {high }}$ ) and effector memory cells (CD44 ${ }^{\text {high }},{ }_{C D 62 L}{ }^{\text {low; }}$ Figure 6a). Thus, expression of either WT or 2KR LAT caused acquisition of a more activated and differentiated phenotype in vivo. To determine whether this was an intrinsic property of LAT-expressing CTLs, naive cells $\left(\mathrm{CD}_{4} 4^{-}, \mathrm{CD}_{2} \mathrm{~L}^{+}\right)$were isolated and labeled with carboxyfluorescein succinimidyl ester (CFSE). Labeled cells were stimulated and various activation markers were evaluated on the days following stimulation. Strikingly, by day 2 following stimulation, the percentage of cells that had upregulated CD44 expression and proliferated was greatly increased in WT or $2 \mathrm{KR}$ LAT-expressing $\mathrm{CD}^{+} \mathrm{T}$ cells compared with $\mathrm{TG}^{-}$controls (Figure $6 \mathrm{~b}$ ). These results indicate that LAT expression causes cells to rapidly differentiate, a phenotype that has been associated with suboptimal immunity and effectiveness for tumor clearance.

\section{DISCUSSION}

In this manuscript we present a comprehensive comparison of the functional profile of transgenic mice expressing WT or ubiquitinresistant $2 \mathrm{KR}$ LAT in postthymic $T$ cells. The LAT constructs expressed in these mice were designed to interrogate the role of LAT ubiquitination in mature $T$ cells, without affecting T-cell development. Consistent with studies in human cell lines and primary human $T$ cells, murine $T$ cells expressing $2 \mathrm{KR}$ LAT displayed enhanced TCR-dependent signaling in various in vitro assays. Furthermore, enhanced T-helper cell function was observed in vivo. Surprisingly, however, when the mice were
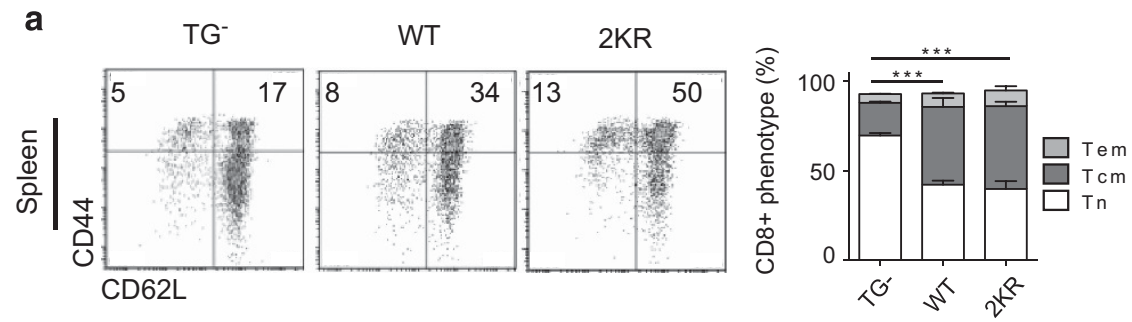

b
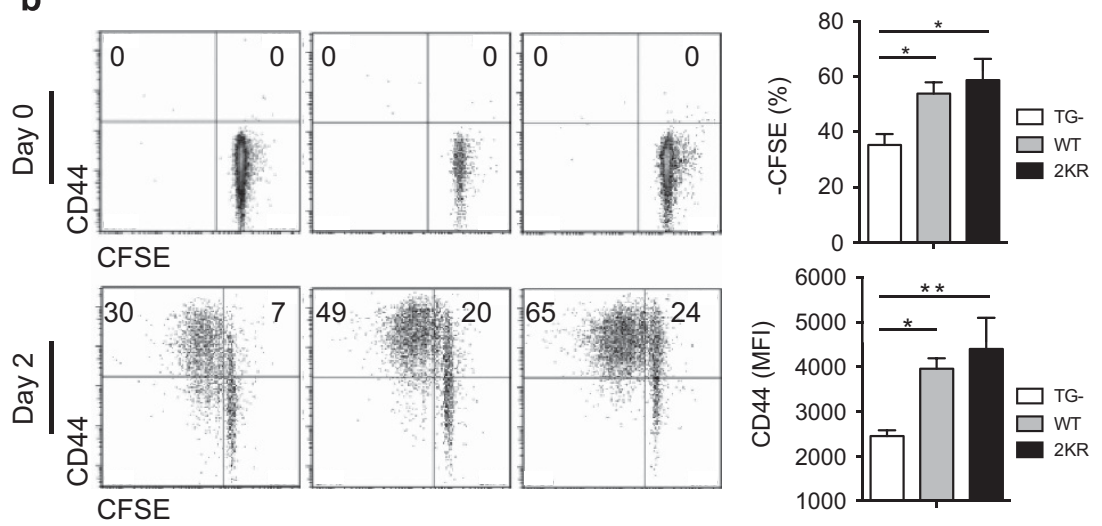

Figure 6. Acquisition of effector phenotype due to LAT expression. (a) Evaluation of effector memory (Tem), central memory (Tcm) and naive T (Tn) cells in spleens from indicated age-matched mice, $n=3$. (b) $C D 8^{+}$naive T cells $\left(\mathrm{CD}_{4} 4^{-} \mathrm{CD} 62 \mathrm{~L}^{+}\right)$were CFSE-labeled and stimulated on antiCD3-coated $\left(1 \mu \mathrm{g} \mathrm{ml}^{-1}\right)$ plates in presence of soluble anti-CD28 $\left(2 \mu \mathrm{g} \mathrm{ml}^{-1}\right)$. At days indicated, cells were evaluated for the dilution of CFSE and the acquisition of memory $\left(\mathrm{CD} 44^{+}\right), n=3 .{ }^{*} P \leqslant 0.05,{ }^{* *} P \leqslant 0.01,{ }^{* * *} P \leqslant 0.001$. 
challenged to clear pathogens, expression of WT or 2KR LAT was not beneficial. Notably, expression of transgenic WT LAT also increased T-cell signaling in various assays, indicating that LAT is a limiting component of the signaling pathway that mediates several immune responses of mature $\mathrm{CD}^{+}$and $\mathrm{CD}^{+} \mathrm{T}$ cells in response to antigen.

The enhanced signaling in $\mathrm{CD}^{+} \mathrm{T}$ cells expressing $2 \mathrm{KR}$ LAT also prompted us to examine whether LAT or 2KR LAT expression in CTLs augmented tumor clearance. Recent clinical trials have shown that transfer of genetically modified $T$ cells can result in substantial antitumor activity. ${ }^{25,27}$ In addition to expression of high affinity TCRs, chimeric antigen receptors and costimulatory molecules at the cell surface, targeting of key signaling molecules may offer new approaches to modify the activity of $T$ cells in cancer and other pathologies. Ablation of $\mathrm{Cbl}-\mathrm{b},{ }^{28}$ deletion of diacylglycerol kinase- ${ }^{29}$ and knockdown of phosphatase Ppp2r $2 d^{30}$ have been suggested as approaches to improve antigen signaling in transferred $\mathrm{T}$ cells. However, despite enhanced cytotoxic activity in vitro, expression of WT or 2KR LAT did not enhance tumor clearance.

Expression of both WT and 2KR LAT caused spontaneous acquisition of a more activated and differentiated phenotype. After antigen encounter, naive $T$ cells differentiate to central memory and then into terminally differentiated short-lived effector memory $T$ cells. During this process of maturation, $T$ cells progressively acquire effector functions but simultaneously lose their capacities for self-renewal and survival. This differentiation can enhance effectiveness in protection against acute viral infections. ${ }^{31-33}$ However, no benefit in protection was observed in the influenza model tested. In this regard, generation of a 2KR LAT knock-in mouse may be advantageous and contrast with that of the transgenic, both because of a more physiological control of transgene expression as well as elimination of endogenous LAT expressed in the T cells. In contrast to increased efficacy in acute viral infection models, increased differentiation is thought to diminish therapeutic effectiveness in chronic infections and tumor models. $^{21,34}$ In mice, adoptive cell transfer of less-differentiated subsets have regularly demonstrated superior in vivo expansion, persistence and antitumor capacities relative to the more differentiated cells. In human clinical trials of adoptive immunotherapy, detailed retrospective analyses indicate that transfer of less-differentiated T-cell subsets is correlated with better clinical responses (reviewed in ref. 20). Thus, the more differentiated phenotype of LAT-expressing cells, either right out of LATexpressing mice or in in vitro culture, was not efficacious in tumor clearance.

To avoid spontaneous differentiation of T cells associated with constitutive LAT expression, a number of alternative approaches may be pursued. First, generation of an inducible 2KR LAT knockin mouse may decrease the percentage of differentiated cells in the adoptively transferred pool. Another approach would be to use a nuclear factor of activated T cells-responsive promoter to restrict LAT expression to the tumor microenvironment in activated T cells triggered by specific tumor antigen recognition. This approach has been used successfully in murine models of adoptive T-cell therapy, to provide the benefits of IL-12 expression in the tumor environment, while avoiding cell toxicity issues caused by constitutive IL-12 expression. ${ }^{35}$ In addition, several approaches such as treatment with cytokines or antibodies to suppress differentiation or mediate revival of terminally differentiated T cells are being actively pursued. ${ }^{36,37}$ Whether these approaches can be used to arrest or reverse T-cell differentiation, while still retaining enhanced function in LAT-expressing cells, will need to be evaluated.

In summary, our data reinforce the role of LAT ubiquitination in TCR signaling. We have shown that LAT is a limiting component of the signaling pathway that mediates several immune responses of mature $\mathrm{CD}^{+}$and $\mathrm{CD}^{+}{ }^{+}$cells in response to antigen, with the functional consequence of providing more LAT evident at the molecular and cellular level. In addition, we have uncovered a novel role for LAT in driving T-cell differentiation. Despite greater T-cell function in various in vitro assays and in vivo, in T-dependent immune responses, WT or 2KR LAT expression did not have a beneficial effect on pathogen or tumor clearance. Thus, in vivo studies of a given genetic modifier of an immune response and how it affects immunotherapy are warranted, as enhanced in vitro activity of $\mathrm{T}$ cells is an inadequate predictor of increased in vivo efficacy. Future studies will focus on immunotherapy approaches that harness the increased potency of ubiquitin-defective 2KR LAT while avoiding increased differentiation by directing LAT expression immediately before adoptive transfer of $\mathrm{T}$ cells or directly in the tumor microenvironment.

\section{MATERIALS AND METHODS}

Design and characterization of WT LAT and 2KR LAT expression constructs: cloning strategy

Murine WT LAT complementary DNA (CDNA) was inserted into EcoRI and Xhol cloning sites of the pBluescript II KS (+) vector (Fermentas, Rockville, MD, USA). Lysines of murine WT LAT CDNA were substituted with arginines to obtain 2KR LAT (QuickChange Multi Site-Directed Mutagenesis Kit, Stratagene, La Jolla, CA, USA). A sequence bearing a flexible linker, three sequences of hemaglutinin tag and a stop codon was inserted in $3^{\prime}$ end of both LAT WT and LAT 2KR cDNAs. Bg/ll restriction enzyme sites flanking WT LAT or 2KR LAT sequences permitted insertion of the CDNAs into BamH cloning site of pCDNA3 expression vectors (Invitrogen, Grand Island, NY, USA) and to validate LAT transgenic constructs. Mutations were confirmed by DNA sequencing.

To establish a transgenic model with specific transgene expression in mature thymocytes and peripheral T lymphocytes, the murine-coding sequence of either WT LAT or 2KR LAT tagged with hemaglutinin was subcloned into the BamHI site of the dLck expression vector, which contains the lck distal promoter. The human growth hormone gene ( $h G H)$ $3^{\prime}$ tail was additionally included in the expression vector to provide a polyadenylation signal as a transcriptional stop sequence.

\section{Generation of WT LAT and 2KR LAT transgenic mice}

The pronucleus of C57BL/6 fertilized mouse eggs was microinjected with Notl-digested and linearized WT LAT or 2KR LAT expression constructs. Founder mice were confirmed to harbor the corresponding constructs by Southern blot analysis with a $32 \mathrm{P}$-labeled probe encompassing the microinjected fragment following BamHI digestion of genomic mouse DNA.

\section{Detection of LAT transgenes and establishment of independent} mouse lines

Transgenic offspring were identified by PCR screening using DNA extracted from ear samples. The following set of primer pairs detected a PCR product for genomic mLAT DNA of 294 bp: exon 1, 5'-TGGAAGCAGAC GCCTTGAGC-3'; and exon 2/intron, 5'-GCTGTCATAGGAGACTGGAGGAAAG $-3^{\prime}$. The following set of primers detected a PCR product for mLAT CDNA of 468 bp: exon 1, 5'-TGGAAGCAGACGCCTTGAGC-3'; and exon 8, 5'-GCACAG GAGCAGAGGAGACAAC-3'. Primers were designed by using MacVector software.

To check the spatial and temporal expression pattern of the LAT transgene regulated by Lck promoter, single-cell suspensions of thymocytes or LN cells were obtained, and LAT was detected by flow cytometric analysis as indicated below. To establish independent mouse lines, the amount of endogenous and transgenic LAT expressed by mature lymphocytes was measured by western blotting in both $\mathrm{CD} 4^{+}$and $\mathrm{CD} 8^{+}$ purified LN cells from transgene-negative littermates $\left(\mathrm{TG}^{-}\right)$, WT LAT and 2KR LAT mice. Independent mouse lines were chosen based on transgene expression levels measured in $L N$ cells by western blotting as the ratio of transgenic/endogenous LAT.

WT LAT or 2KR LAT mice generated as described above were intercrossed for five to seven generations to $\mathrm{C} 57 \mathrm{BL} / 6 \mathrm{NCr}$ mice obtained from the National Cancer Institute (Frederick) and experiments were performed in 6- to 8-week-old animals. OT-I TCR transgenic animals, purchased from The Jackson Laboratory, were backcrossed to WT LAT or 
2KR LAT mice and animals were used from 8 to 12 weeks of age. Animals were housed at National Cancer Institute (Frederick) or at the Center for Biologics Evaluation and Research and maintained in accordance with guidelines of the National Cancer Institute-Frederick Animal Care and Use Committee at the $\mathrm{NIH}$. All the experiments performed were approved by the Animal Care and Use Committee of the NIH or of Center for Biologics Evaluation and Research .

\section{Ubiquitination of transgenic constructs}

To evaluate ubiquitination of LAT transgenic constructs, COS-7 cells were transfected as described previously (7) with either WT LAT or 2KR LAT DNAs inserted in pcDNA3 vectors. Whole-cell lysates of transfected cells were processed for corresponding immunoprecipitation and immunoblotting as previously described, with the addition of $10 \mathrm{mM} \mathrm{N}$-ethylmaleimide to the lysis buffer.

\section{T-cell isolation and flow cytometric sorting}

Thymus, LN and spleens of TG- ${ }^{-}$WT LAT or 2KR LAT mice were disrupted by mechanical dissection, and single-cell suspensions were prepared in Roswell Park Memorial Institute medium (RPMI) 1640 (Sigma, St Louis, MO, USA) by using 70- $\mu \mathrm{m}$ nylon cell strainers (BD Biosciences, San Jose, CA, USA). Red blood cell lysis was additionally performed in spleen samples using ACK lysing buffer (Quality Biological, Inc., Gaithersburg, MD, USA). Lymphoctyes from the lamina propria and the mesenteric lymph nodes were prepared as previously described. ${ }^{38}$

To isolate $\mathrm{CD}^{+}$or $\mathrm{CD}^{+}$naive T cells, pooled splenic and LN cells were negatively selected by using the corresponding mouse $\mathrm{CD} 4^{+}$or $\mathrm{CD} 8^{+} \mathrm{T}$-cell enrichment kits (\#19752 or \#19753, Stemcell Technologies, Vancouver, BC, Canada). Purified T cells were then stained at 1:500 dilution each with antiCD44-FITC (\#553133, BD Pharmingen, San Jose, CA, USA), anti-CD62L-PE (\#553151, BD Pharmingen), anti-CD25-PeCy7 (\#25-0251, eBioscience, San Diego, CA, USA), anti-CD4-APC (\#553051, BD Pharmingen), or anti-CD8a-PerCP (\#553036, BD Pharmingen). Stained T cells were sorted on a FACsAria (BD Biosciences) to obtain naive $\mathrm{CD} 4{ }^{+} \mathrm{CD} 44^{\mathrm{lo}} \mathrm{CD} 62 \mathrm{~L}^{\mathrm{hi}} \mathrm{CD} 25^{-}$ or $\mathrm{CD} 8{ }^{+} \mathrm{CD} 44^{\mathrm{lo}} \mathrm{CD} 62 \mathrm{~L}^{\mathrm{hi}} \mathrm{CD} 25^{-}$cells at a purity $>99 \%$. $\mathrm{T}_{\text {regs }}$ were isolated by sorting for $\mathrm{CD}^{+} \mathrm{CD}_{2} 5^{\text {high }} \mathrm{T}$ cells from spleen and LN from TG ${ }^{-}$, WT and 2KR mice. T-depleted splenocytes as antigen-presenting cells (APCs) were isolated as previously described. ${ }^{39}$

\section{T-cell culture and flow cytometric analysis}

Sorted $\mathrm{CD}^{+}$or $\mathrm{CD}^{+}$naive $\mathrm{T}$ cells $\left(1 \times 10^{5}\right)$ were cultured in complete medium (RPMI 1640, 10\% fetal calf serum, $2 \mathrm{~mm} \mathrm{L-glutamine,} 100 \mathrm{U} \mathrm{ml}^{-1}$ penicillin, $100 \mathrm{\mu g} \mathrm{ml}^{-1}$ streptomycin, $1 \mathrm{~mm}$ sodium pyruvate, $1 \%$ nonessential amino acids, $0.1 \% \quad \beta$-mercaptoethanol) for $72 \mathrm{~h}$ in roundbottomed 96-well plates containing $0.075 \mathrm{\mu g} \mathrm{ml}^{-1}$ anti-CD3E (\#624092, BD Pharmingen) and $5 \mathrm{\mu g} \mathrm{ml}^{-1}$ anti-CD28 (\#553294, BD Pharmingen). Cultured T cells were then restimulated for $4 \mathrm{~h}$ with phorbol 12-myristate 13-acetate $\left(0.3 \mu \mathrm{g} \mathrm{ml}^{-1}\right.$, Sigma) and ionomycin $\left(1 \mu \mathrm{g} \mathrm{ml} l^{-1}\right.$, Sigma) with addition of protein transport inhibitor $\left(2 \mu \mathrm{ml}^{-1}\right.$, BD GolgiStop, \#51-2092KZ, BD Biosciences). Cells were fixed and permeabilized (Cytofix/Cytoperm Plus Fixation/Permeabilization kit, BD Biosciences) to evaluate intracellular cytokine production by flow cytometry with following antibodies: antitumor necrosis factor-a-FITC (1:200, \#53-732182, eBioscience), anti-IL-2-PerCPCy5.5 (1:500, \#45-7021 eBioscience), antiIFN- $\gamma$-Pacific blue (1:1000, \#48-7311, eBioscience), anti-CD4-PeCy7 (1:1500, \#25-0042 eBioscience) and anti-CD8-PeCy7 (1:400, \#25-0081, eBioscience).

For basal detection of intracellular cytokines and Foxp3 by flow cytometry, $1 \times 10^{6}$ single T-cell suspensions were in vitro restimulated and then stained with fluorochrome-conjugated antibodies against TCR- $\beta$ chain, CD4, CD8a, IFN- $\gamma$, Foxp3 or isotype controls as previously described. ${ }^{40}$ Nuclear Ki-67 staining of T cells was performed using antiKi-67-PE (1:50, \#556027, BD Pharmingen).

In total, $2 \times 10^{6}$ single-cell suspensions from thymus or LN (axillary, inguinal and brachial) were used to evaluate the expression of transgenic and endogenous LAT and Foxp3 in $\mathrm{CD}^{+}$and $\mathrm{CD} 8^{+}$cells by flow cytometric analysis. The following antibodies were used to detect T-cell surface markers: anti-CD4-PE (1:200, \#553653, BD Pharmingen) and anti-CD8-PerCP (1:50, \#553036, BD Pharmingen). Fixed and permeabilized cells were prepared for intracellular cytokine staining with the following antibodies: anti-LAT (1:1000, Zhang et al., 1998) and anti-hemaglutinin (1:1000, HA.11, Covance, Trenton, NJ, USA). The following secondary fluorochromeconjugated antibodies were used: anti-glutathione S-transferase-Alexa Fluor 488 (1:2000, rabbit IgG fraction, Invitrogen) and APC-goat anti-mouse $\lg \mathrm{G}(\mathrm{H}+\mathrm{L})(1: 15000$, Invitrogen). Conditions and antibodies used to assess thymocyte development and pERK by flow cytometry have been previously described. ${ }^{9}$

Anti-GzmB-PE antibody (1:200, \#GRB04, Invitrogen) was used to detect the abundance of GzmB in $2 \times 10^{6}$ fixed and permeabilized activated cytotoxic lymphocytes (CTLs).

Spleens were harvested as previously indicated and B-cell surface markers were analyzed to detect GC B cells as $B 220^{+} \mathrm{IgD}^{\mathrm{lo}} \mathrm{GL}-7^{\text {hi }} \mathrm{Fas} \mathrm{si}^{\text {hi }}$ population. The following antibodies and dilutions were used to identify GCs: anti-GL-7-FITC (1:100, \#553666, BD Biosciences), anti-Fas-PE (1:100, \#554258, BD Biosciences), anti-B220-PerCP (1:200, \#553093, BD Biosciences) and anti-immunoglobulin D biotin (1:100, \#1120-08, SouthernBiotech, Birmingham, AL, USA). As secondary antibody, streptavidin-APC (1:500, \#554067, BD Pharmingen) was used.

For evaluation of differentiation markers, cells were stained with CFSE (Molecular Probes, Grand Island, NY, USA) and CD44 and CD62L (BD Biosciences).

Cell acquisition was performed on FACSCalibur (Becton Dickinson, Franklin Lakes, NJ, USA) and LSR II (BD Biosciences) flow cytometers. Data analysis was performed using FlowJo software (Tree Star, Inc., Ashland, OR, USA).

\section{In vitro proliferation assay}

In total, $1 \times 10^{5}$ sorted naive $\mathrm{TG}^{-} \mathrm{CD}^{+}$or $\mathrm{CD}^{+}{ }^{+}$cells, isolated as described above, were plated in round-bottomed 96-well plates and incubated for $72 \mathrm{~h}$ in complete RPMI medium with anti-CD3ع/CD28 platebound antibodies at the following concentrations: 0/0, 0.1/0, 0.5/0, 5/0, $0.1 / 5,0.5 / 5$ and $5 / 5 \mathrm{\mu g} \mathrm{ml}^{-1}$. Cells incubated with phorbol 12-myristate $13-$ acetate $\left(0.03 \mu \mathrm{g} \mathrm{ml}^{-1}\right)$ and ionomycin $\left(0.75 \mu \mathrm{g} \mathrm{ml}^{-1}\right)$ were used as a positive control of dividing cells. Samples were pulsed with $1.25 \mu \mathrm{Ci}$ ${ }^{3} \mathrm{H}$-thymidine for $16 \mathrm{~h}$ before being harvested, and a scintillation betacounter was used to measure the radioactivity in DNA recovered from the cells to determine the extent of cell division.

\section{Stimulation of purified T cells and western blotting analysis}

T cells from LNs of WT LAT and 2KR LAT animals were isolated, and CD4 ${ }^{+}$or $\mathrm{CD} 8^{+} \mathrm{T}$ cells were purified by negative selection as described above. The purity of $\mathrm{CD}^{+}$and $\mathrm{CD}^{+}$T cells was confirmed to be $>95 \%$ by fluorescence-activated cell sorting analysis and single-cell suspensions of $1 \times 10^{5}$ cells per $\mathrm{ml}$ RPMI were prepared.

In all, $2.5 \times 10^{6}$ purified $\mathrm{CD}^{+}$or $\mathrm{CD}^{+} \mathrm{T}$ cells per each time point were

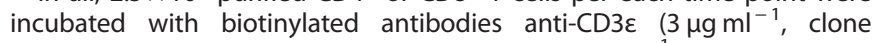
$145-2 \mathrm{C} 11, \mathrm{BD}$ Biosciences) and anti-CD28 $\left(10 \mu \mathrm{g} \mathrm{ml}^{-1}\right.$, clone $37.5, \mathrm{BD}$ Biosciences) for $20 \mathrm{~min}$ at room temperature. Cells were then washed with RPMI 1640 and resuspended at $1 \times 10^{6}$ cells per $10 \mu$ prior to the addition of $40 \mu \mathrm{l} 2 \times$ streptavidin $\left(20 \mu \mathrm{g} \mathrm{ml}^{-1}\right.$ final concentration). Stimulation was terminated by the addition of $2 \times$ sodium dodecyl sulfate sample buffer containing $100 \mathrm{mM}$ dithiothreitol and boiling for $10 \mathrm{~min}$, followed by sonication.

$\mathrm{CD}^{+}$or $\mathrm{CD} 8^{+} \mathrm{T}$ cells were loaded $\left(0.5 \times 10^{6}\right.$ per lane $)$ and separated by sodium dodecyl sulfate- $10 \%$ polyacrylamide gel electrophoresis. Membranes were incubated at $4{ }^{\circ} \mathrm{C}$ overnight with the following primary antibodies: anti-pZAP70 (1:2000, \#2704, Cell Signaling Technology, Beverly, MA, USA), anti ZAP70 (1:2000 (ref. 41)), anti-PLC- $\gamma 1$ pY $^{783}$ (1:500, \#2821, Cell Signaling Technology), anti-PLC- $\gamma 1$ (1:500, sc-7290, Santa Cruz, Dallas, TX, USA); anti-LAT pY'191 (1:1000, \#44-228, Invitrogen), anti-LAT (1:3000 (ref. 42)), anti-pERK (1:1000, \#4370, Cell Signaling Technology); anti-ERK (1:1000, \#4695, Cell Signaling Technology). Corresponding secondary horseradish peroxidase-conjugated antibodies were used at room temperature for $1 \mathrm{~h}$ (Millipore, Billerica, MA, USA) and blots were developed using chemiluminiscence detection ( $(E C L$ reagent (Amersham, Pittsburgh, PA, USA); Super signal West Pico and Super signal West Femto (Pierce, Grand Island, NY, USA)).

\section{T-cell suppression assay}

$\mathrm{T}_{\text {regs }}$ were obtained by sorting for $\mathrm{CD}^{+} \mathrm{CD} 25^{\text {high }}$ from $\mathrm{TG}^{-}$, WT and $2 \mathrm{KR}$ mice. To test the suppressive function of $\mathrm{T}_{\text {regs }}$ in vitro, sorted naive $\mathrm{CD}^{+}$ effector cells from C57BL/ 6 mice at $50 \times 10^{3}$ per well were stimulated with $0.5 \mu \mathrm{g} \mathrm{ml}^{-1}$ anti-CD3 $\varepsilon$ in the presence of mitomycin-treated T-depleted splenocytes as APCs at $50 \times 10^{3}$ per well. Graded numbers $T_{\text {regs }}$ from TG ${ }^{-}$, WT and 2KR cells were added into the culture (as indicated in Supplementary Figure S7). Proliferation was measured by $\left[{ }^{3} \mathrm{H}\right]$ thymidine incorporation after 3 days of culture, as previously described. ${ }^{43}$ 


\section{Calcium flux measurement}

LN cells were freshly isolated as previously indicated from TG ${ }^{-}$, WT LAT or $2 \mathrm{KR}$ LAT mice. In total, $2 \times 10^{7}$ lymphocytes were suspended at $1 \times 10^{7} \mathrm{ml}^{-1}$ (Hank's Balanced Salt Solution, Biofluids; $10 \mathrm{mM}$ hydroxyethyl piperazineethanesulfonic acid (Gibco, Grand Island, NY, USA); $0.5 \mathrm{~mm}$ Probenecid (Sigma) and 1\% fetal bovine serum) and incubated for $45 \mathrm{~min}$ at $30^{\circ} \mathrm{C}$ in a shaking incubator with $10 \mu$ indo- 1 solution in fetal bovine serum $\left(0.36 \mathrm{\mu g} \mathrm{ul}^{-1}\right.$ INDO-1 AM (Invitrogen) containing 3.6\% detergent (Pluronic, Molecular Probes)). Cells were then stained with anti-CD8-PE and anti-CD4-APC (1:100 and 1:200, respectively, BD Pharmingen), and kept at $37^{\circ} \mathrm{C}$. Stimulatory biotinylated antibodies anti-CD3ع $\left(3 \mu \mathrm{g} \mathrm{ml}^{-1}\right)$ and antiCD28 $\left(10 \mu \mathrm{g} \mathrm{ml}^{-1}\right)$ were added to $2.5 \times 10^{6} \mathrm{LN}$ cells. Samples were run for $30 \mathrm{~s}$ using an LSR II (BD Biosciences) and streptavidin $\left(20 \mathrm{\mu g} \mathrm{m}^{-1}\right)$ was added to monitor the calcium flux for $5 \mathrm{~min}$ as the ratio of indo-violet/ indo-blue by flow cytometry.

\section{Generation of effector CTLs and maintenance of target cells}

Single-cell suspensions of splenocytes were derived from 8- to 12-week-old OT-1, WT LAT OT-I or 2KR LAT OT-I mice and cultured at $1 \times 10^{6}$ cells per ml for 3 days in complete medium RPMI 1640 with soluble $10 \mathrm{~nm}$ OVA $_{257-264}$ (SIINFEKL) peptide, which is an epitope of OVA presented by the class 1 major histocompatibility complex molecule, $\mathrm{H}-2 \mathrm{~K}^{\mathrm{b}}$. On day 3 , cells were washed and maintained at $1 \times 10^{5}$ cells per $\mathrm{ml}$ in complete medium containing $10 \mathrm{U} \mathrm{ml}^{-1}$ recombinant human IL-2 for 2 days. On day 5 following primary stimulation, CTLs were separated by centrifugation with lymphocyte separation medium (\#50494X, MP Biomedicals, LLC, Santa Ana, (A, USA) and cultured at $1 \times 10^{5}$ cells per $\mathrm{ml}$ in complete medium with $10 \mathrm{U} \mathrm{ml}^{-1} \mathrm{IL}-2$. After 6 days of culture, the cytotoxic activities of OT-I, WT LAT OT-I and 2KR LAT OT-I CTLs were examined by in vitro cytotoxicity assay against $\mathrm{H}-2 \mathrm{~K}^{\mathrm{b}}$ EL4 mouse thymoma cell line. EL4 target cells were maintained in Dulbecco's Modified Eagle's medium with $2 \%$ fetal calf serum, $2 \mathrm{mM}$ l-glutamine, $100 \mathrm{U} \mathrm{ml}^{-1}$ penicillin and $100 \mu \mathrm{g} \mathrm{ml}^{-1}$ streptomycin.

\section{Flow-based cytotoxicity assay}

EL4 target cells were washed with phosphate-buffered saline and labeled with $100 \mathrm{~nm}$ carboxyfluorescein diacetate succinimidyl ester (CellTrace CFSE Cell proliferation kit, Invitrogen) for $10 \mathrm{~min}$ at $37^{\circ} \mathrm{C}$. The reaction was stopped by addition of ice-cold phosphate-buffered saline and cells were washed with phosphate-buffered saline followed by RPMI supplemented with $2 \%$ fetal calf serum, $100 \mathrm{U} \mathrm{ml}^{-1}$ penicillin and $100 \mathrm{\mu g} \mathrm{ml}^{-1}$ streptomycin. In all, $2 \times 10^{6}$ CFSE-labeled EL4 target cells, suspended in supplemented RPMl, were pulsed with $30 \mathrm{nM}$ OVA peptide for $1 \mathrm{~h}$ at $37^{\circ} \mathrm{C}$ and washed three times in supplemented RPMI. CFSE-pulsed target cells were suspended at $10^{5}$ cells per $\mathrm{ml}$ in killing assay medium (phenol red free RPMI 1640, Gibco supplemented with $2 \%$ fetal calf serum, $100 \mathrm{U} \mathrm{ml}^{-1}$ penicillin and $100 \mathrm{\mu g} \mathrm{ml}^{-1}$ streptomycin) and cytolytic activity was measured after $4 \mathrm{~h}$ of incubation with 6-day-activated OT-I, WT LAT OT-I or 2KR LAT OT-I CD8 ${ }^{+}$splenocytes for a range of effector to target ratios. The reaction was in $200 \mu \mathrm{l}$ of killing assay media and assays were run in duplicates in 96-well round-bottom microplates. To detect dead cells, plates were placed on ice and $1.5 \mu \mathrm{l}$ 7-aminoactinomycin D (7-AAD, BD Pharmingen) was added to each well immediately flow cytometry. Cell death was analyzed by flow cytometry after gating on the CFSE-positive population. The population of CFSE ${ }^{+} 7-\mathrm{AAD}^{+}$cells represented the target cells that have been killed and $\mathrm{CFSE}^{+} 7-\mathrm{AAD}^{-}$population represented the remaining viable target cells. Percentage of specific lysis was calculated by using the formula: specific lysis $(\%)=100-\left(\left(\right.\right.$ viable CFSE $^{+}$target cells in contact with CTL/viable CFSE ${ }^{+}$target cells alone) $\times 100$ ).

Mouse immunizations and analysis of immunoglobulins by ELISA To evaluate primary antibody responses to defined antigens, TG- ${ }^{-}$, WT LAT and 2KR LAT mice were subjected to standard immunization protocols. To study T-dependent responses, mice received intraperitoneal injection of $100 \mu \mathrm{g} \mathrm{NP}-\mathrm{KLH}$ (NP(28)-KLH: 4-hydroxy-3-nitrophenyl acetyl-keyhole limpet hemocyanin; N-5060-25, Biosearch Technologies, Novato, CA, USA) in $100 \mu \mathrm{l}$ phosphate-buffered saline buffer precipitated in $100 \mu \mathrm{l}$ Imject Alum adjuvant (\#77161, Thermo Scientific, Grand Island, NY, USA). T-independent responses were followed in mice injected intraperitoneally with $100 \mu \mathrm{g}$ NP-lipopolysaccharide(4-Hydroxy-3-nitrophenyl acetyl hapten conjugated to lipopolysaccharide; N-5065, 60\%, Biosearch Technologies) in $200 \mu \mathrm{l} \mathrm{Hank's} \mathrm{Balanced} \mathrm{Salt} \mathrm{Solution.} \mathrm{Preimmune} \mathrm{sera} \mathrm{and} \mathrm{sera} \mathrm{obtained} \mathrm{at}$ indicated end-point bleedings were tested for detection of $\operatorname{lgG}_{1}, \lg _{2 b}$ and $\mathrm{IgG}_{3}$ anti-NP antibodies by ELISA. Spleens were harvested as previously indicated for flow cytometric analysis to detect GC B cells.

ELISA was used to detect antigen-specific (NP) serum antibody levels in immunized mice. Ninety-six-well flat bottom immunoplates (Nunc) were coated overnight at $4{ }^{\circ} \mathrm{C}$ with NP-bovine serum albumin $(2.5 \mu \mathrm{g}$ per well, $\mathrm{N}-5050 \mathrm{H}-10$, Biosearch Technologies). Plates were blocked with $1 \%$ bovine serum albumin for $30 \mathrm{~min}(\mathrm{RT})$ and incubated overnight $\left(4^{\circ} \mathrm{C}\right)$ with serial dilutions of mouse serum. Horseradish peroxidase-conjugated goat antimouse antibodies specific for $\operatorname{lgG}_{1}, \operatorname{lgG}_{2 b}$ and $\operatorname{lgG}_{3}$ (SouthernBiotech) 1:1000 diluted were used to measure serum antibody levels after incubating the plates overnight $\left(4^{\circ} \mathrm{C}\right)$. Developing substrate was added (ABTS 1-Component microwell peroxidase substrate kit, $\mathrm{KPL}$ ) and plates were read with an ELISA plate reader at OD $405 \mathrm{~nm}$.

\section{Induction and scoring of Experimental Autoimmune} Encephalomyelitis

Mice were immunized with $\left(\mathrm{MOG}_{35-55}\right)$ emulsified 1:1 vol/vol in complete Freund's adjuvant that had been supplemented with Mycobacterium tuberculosis strain H37RA to $4.0 \mathrm{mg} \mathrm{ml}^{-1}$. A total of $200 \mu \mathrm{l}$ of emulsion was injected subcutaneously, divided among three sites: base of tail and both thighs. As additional adjuvant, $0.3 \mu \mathrm{g}$ of Bordetella pertussis toxin (Sigma) was administered on the same day. Clinical scores were evaluated starting on day 7 following the grading system described previously. ${ }^{44}$

Induction and scoring of Experimental Autoimmune Uveoretinitis Mice were immunized with a mixture of $150 \mu \mathrm{g}$ of whole-bovine interphotoreceptor retinoid-binding protein $\left(\mathrm{IRBP}^{45}\right)$ plus $300 \mu \mathrm{g}$ human $\mathrm{IRBP}_{1-20}$ (AnaSpec, Fremont, CA, USA). The antigens were emulsified 1:1 $\mathrm{vol} / \mathrm{vol}$ in complete Freund's adjuvant that had been supplemented with Mycobacterium tuberculosis strain H37RA (Sigma) to $2.5 \mathrm{mg} \mathrm{ml}^{-1}$. A total of $200 \mu \mathrm{l}$ of emulsion was injected subcutaneously, divided among three sites: base of tail and both thighs. As additional adjuvant, $0.5 \mu \mathrm{g}$ of Bordetella pertussis toxin (Sigma) was administered on the same day. Eyes were harvested 21 days after immunization, prefixed in $4 \%$ phosphatebuffered glutaraldehyde for $1 \mathrm{~h}$ and then transferred to $10 \%$ phosphatebuffered formaldehyde. Fixed and dehydrated tissue was embedded in methacrylate, and 4-6- $\mu \mathrm{m}$ sections were stained with standard hematoxylin and eosin. Eyes were scored in a masked fashion by an ophthalmic pathologist on a scale of 0 (no disease) to 4 (maximum disease) in halfpoint increments according to a semiquantitative system described previously. ${ }^{46}$

\section{Parasitic and viral infections}

For parasitic studies, female TG ${ }^{-}$, LAT WT or 2KR LAT mice were infected by orally gavaging with eight cysts of a red fluorescent protein expressing C1 clone of the ME-49 T. gondii strain. The red fluorescent protein was used so that parasite could be detected via fluorescence-activated cell sorting analysis for quantitation of parasite burden in the analyzed tissues. Conditions of parasite maintenance and cyst preparation have been previously published..$^{40}$ At day 9 after sublethal infection with eight cysts, lymphocytes from spleen, lamina propria or mesenteric lymph nodes were harvested to analyze intracellular cytokine production by flow cytometry as indicated above. T. gondii-red fluorescent protein burden was measured by flow cytometry within the total live CD45.2-positive cell population isolated from spleen, lamina propria or mesenteric lymph nodes compartments of WT LAT and 2KR LAT animals.

For studies of influenza virus infection, TG $^{-}$, LAT WT or $2 \mathrm{KR}$ LAT mice were intranasally inoculated under isoflurane anesthesia with $25 \mu \mathrm{l}$ per nostril containing $10^{2} \mathrm{TCID}_{50}$ of influenza A virus A/Puerto Rico/8/1934 (A/ $\mathrm{PR} / 8 / 34)$, (H1N1). Virus stock was prepared as previously described. ${ }^{47}$ In brief, influenza virus was propagated in the allantoic cavity of embryonated hen eggs at $34^{\circ} \mathrm{C}$ for $48-72 \mathrm{~h}$ and frozen at $-70^{\circ} \mathrm{C}$ until use. Animals were individually weighed to evaluate morbidity, and were monitored for survival for 15 days.

\section{Adoptive immunotherapy}

For immunotherapy, C57BL/6 mice were implanted with subcutaneous B16 melanoma $\left(5 \times 10^{5}\right.$ cells) or B16/OVA melanoma $\left(5 \times 10^{5}\right.$ cells). At the time of adoptive cell transfer 10-14 days post implantation, tumor-bearing mice were irradiated with 500 rads. B16/OVA tumor-bearing mice were injected intravenously with $\mathrm{CD} 88^{+}$-enriched or isolated naive $\left(\mathrm{CD} 8^{+} \mathrm{CD} 6 \mathrm{~L}^{+} \mathrm{CD} 44^{-}\right)$ 
OT-I, WT LAT OT-I or 2KR LAT OT-I splenocytes $\left(1 \times 10^{6}\right.$ cells). Another set of mice bearing B16 melanoma were injected intravenously with in vitro activated splenocytes transduced with pmel- 1 TCR $\left(1 \times 10^{6} \mathrm{CD}^{+}\right.$cells $)$, and $2 \times 10^{7}$ plaque-forming units of recombinant vaccinia virus encoding hgp100. All mice except the no treatment group received intraperitoneally 30000 CU of recombinant human IL-2 twice daily for 3 days following adoptive transfer. Mice were randomized, and tumors were blindly measured using digital calipers.

\section{Statistical analysis}

Data were analyzed with Graph-Pad Prism software. Statistical significance between two groups was calculated with two-tailed $t$-tests. Statistical differences among several groups were determined by using two-way analysis of variance. Data were expressed as mean \pm s.e.m. Values of ${ }^{*} P<0.05,{ }^{* *} P<0.01,{ }^{* * *} P<0.001$ were considered significant.

\section{CONFLICT OF INTEREST}

The authors declare no conflict of interest.

\section{ACKNOWLEDGEMENTS}

We thank Paul Love for providing the dLck expression vector, Wenmei Li and Terri Stull for technical support, F Zhao, Jennifer Cannons and Kristina Lu for helpful advice in cytotoxicity and immunization experiments, The EL4 mouse thymoma $\left(\mathrm{H}-2 \mathrm{~K}^{\mathrm{b}}\right)$ cell line was a kind gift from Carol Clayberger. This research was supported by the Intramural Research Program of the National Institutes of Health, National Cancer Institute, Center for Cancer Research. Ana B Rodríguez-Peña was additionally supported by Fondo de Investigaciones Sanitarias, Instituto de Salud Carlos III, Ministerio de Economía y Competitividad, Spain.

\section{REFERENCES}

1 Balagopalan L, Coussens NP, Sherman E, Samelson LE, Sommers CL. The LAT story: a tale of cooperativity, coordination, and choreography. Cold Spring Harb Perspect Biol 2010; 2: a005512.

2 Samelson LE. Signal transduction mediated by the T cell antigen receptor: the role of adapter proteins. Annu Rev Immunol 2002; 20: 371-394.

3 Balagopalan L, Barr VA, Sommers CL, Barda-Saad M, Goyal A, Isakowitz MS et al. c-Cbl-mediated regulation of LAT-nucleated signaling complexes. Mol Cell Biol 2007; 27: 8622-8636.

4 Jang IK, Gu H. Negative regulation of TCR signaling and T-cell activation by selective protein degradation. Curr Opin Immunol 2003; 15: 315-320.

5 Ma A, Malynn BA. A20: linking a complex regulator of ubiquitylation to immunity and human disease. Nat Rev Immunol 2012; 12: 774-785.

6 Malynn BA, Ma A. Ubiquitin makes its mark on immune regulation. Immunity 2010; 33: 843-852.

7 Balagopalan L, Ashwell BA, Bernot KM, Akpan IO, Quasba N, Barr VA et al. Enhanced T-cell signaling in cells bearing linker for activation of T-cell (LAT) molecules resistant to ubiquitylation. Proc Natl Acad Sci USA 2011; 108: 2885-2890.

8 Kunii N, Zhao Y, Jiang S, Liu X, Scholler J, Balagopalan L et al. Enhanced function of redirected human $T$ cells expressing linker for activation of $T$ cells that is resistant to ubiquitylation. Hum Gene Ther 2013; 24: 27-37.

9 Kortum RL, Sommers CL, Pinski JM, Alexander CP, Merrill RK, Li W et al. Deconstructing Ras signaling in the thymus. Mol Cell Biol 2012; 32: 2748-2759.

10 Wildin RS, Wang HU, Forbush KA, Perlmutter RM. Functional dissection of the murine Ick distal promoter. J Immunol 1995; 155: 1286-1295.

11 Kortum RL, Sommers CL, Alexander CP, Pinski JM, Li W, Grinberg A et al. Targeted Sos 1 deletion reveals its critical role in early T-cell development. Proc Natl Acad SCi USA 2011; 108: 12407-12412.

12 Hogquist KA, Jameson SC, Heath WR, Howard JL, Bevan MJ, Carbone FR. T cell receptor antagonist peptides induce positive selection. Cell 1994; 76: 17-27.

13 Cannons JL, Yu LJ, Jankovic D, Crotty S, Horai R, Kirby M et al. SAP regulates T cellmediated help for humoral immunity by a mechanism distinct from cytokine regulation. J Exp Med 2006; 203: 1551-1565.

14 Epstein SL, Price GE. Cross-protective immunity to influenza A viruses. Expert Rev Vaccines 2010; 9: 1325-1341.

15 Gazzinelli R, Xu Y, Hieny S, Cheever A, Sher A. Simultaneous depletion of CD4+ and CD8+ T lymphocytes is required to reactivate chronic infection with Toxoplasma gondii. J Immunol 1992; 149: 175-180.
16 t Hart BA, Gran B, Weissert R. EAE: imperfect but useful models of multiple sclerosis. Trends Mol Med 2011; 17: 119-125.

17 Caspi RR. A look at autoimmunity and inflammation in the eye. J Clin Invest 2010; 120: $3073-3083$

18 Overwijk WW, Theoret MR, Finkelstein SE, Surman DR, de Jong LA, Vyth-Dreese FA et al. Tumor regression and autoimmunity after reversal of a functionally tolerant state of self-reactive CD8+ T cells. J Exp Med 2003; 198: 569-580.

19 Palmer DC, Chan CC, Gattinoni L, Wrzesinski C, Paulos CM, Hinrichs CS et al. Effective tumor treatment targeting a melanoma/melanocyte-associated antigen triggers severe ocular autoimmunity. Proc Natl Acad Sci USA 2008; 105: 8061-8066.

20 Klebanoff CA, Gattinoni L, Restifo NP. Sorting through subsets: which T-cell populations mediate highly effective adoptive immunotherapy? I Immunother 2012; 35: 651-660.

21 Gattinoni L, Klebanoff CA, Palmer DC, Wrzesinski C, Kerstann K, Yu Z et al. Acquisition of full effector function in vitro paradoxically impairs the in vivo antitumor efficacy of adoptively transferred CD8+ T cells. J Clin Invest 2005; 115: 1616-1626.

22 Hinrichs CS, Borman ZA, Cassard L, Gattinoni L, Spolski R, Yu Z et al. Adoptively transferred effector cells derived from naive rather than central memory CD8+ T cells mediate superior antitumor immunity. Proc Natl Acad Sci USA 2009; 106: 17469-17474.

23 Hinrichs CS, Borman ZA, Gattinoni L, Yu Z, Burns WR, Huang J et al. Human effector CD8+ $T$ cells derived from naive rather than memory subsets possess superior traits for adoptive immunotherapy. Blood 2011; 117: 808-814.

24 Klebanoff CA, Gattinoni L, Torabi-Parizi P, Kerstann K, Cardones AR, Finkelstein SE et al. Central memory self/tumor-reactive CD8+ T cells confer superior antitumor immunity compared with effector memory T cells. Proc Natl Acad Sci USA 2005; 102: 9571-9576.

25 Restifo NP, Dudley ME, Rosenberg SA. Adoptive immunotherapy for cancer: harnessing the T cell response. Nat Rev Immunol 2012; 12: 269-281.

26 Gattinoni L, Powell DJ Jr., Rosenberg SA, Restifo NP. Adoptive immunotherapy for cancer: building on success. Nat Rev Immunol 2006; 6: 383-393.

27 Kalos $\mathrm{M}$, June $\mathrm{CH}$. Adoptive T cell transfer for cancer immunotherapy in the era of synthetic biology. Immunity 2013; 39: 49-60.

28 Stromnes IM, Blattman JN, Tan X, Jeevanjee S, Gu H, Greenberg PD. Abrogating Cbl-b in effector CD8(+) T cells improves the efficacy of adoptive therapy of leukemia in mice. J Clin Invest 2010; 120: 3722-3734.

29 Riese MJ, Wang LC, Moon EK, Joshi RP, Ranganathan A, June CH et al. Enhanced effector responses in activated CD8+ T cells deficient in diacylglycerol kinases. Cancer Res 2013; 73: 3566-3577.

30 Zhou P, Shaffer DR, Alvarez Arias DA, Nakazaki Y, Pos W, Torres AJ et al. In vivo discovery of immunotherapy targets in the tumour microenvironment. Nature 2014; 506: 52-57.

31 Price GE, Soboleski MR, Lo CY, Misplon JA, Quirion MR, Houser KV et al. Singledose mucosal immunization with a candidate universal influenza vaccine provides rapid protection from virulent $\mathrm{H} 5 \mathrm{~N} 1, \mathrm{H} 3 \mathrm{~N} 2$ and $\mathrm{H} 1 \mathrm{~N} 1$ viruses. PloS One 2010; 5: e13162.

32 Cerwenka A, Morgan TM, Dutton RW. Naïve, effector, and memory CD8 T cells in protection against pulmonary influenza virus infection: homing properties rather than initial frequencies are crucial. J Immunol 1999; 163: 5535-5543.

33 Price GE, Soboleski MR, Lo CY, Misplon JA, Pappas C, Houser KV et al. Vaccination focusing immunity on conserved antigens protects mice and ferrets against virulent H1N1 and H5N1 influenza A viruses. Vaccine 2009; 27: 6512-6521.

34 Wherry EJ, Ahmed R. Memory CD8 T-cell differentiation during viral infection. J Virol 2004; 78: 5535-5545.

35 Zhang L, Kerkar SP, Yu Z, Zheng Z, Yang S, Restifo NP et al. Improving adoptive T cell therapy by targeting and controlling IL-12 expression to the tumor environment. Mol Ther 2011; 19: 751-759.

36 Araki K, Youngblood B, Ahmed R. Programmed cell death 1-directed immunotherapy for enhancing T-cell function. Cold Spring Harb Symp Quant Biol 2014.

37 Hinrichs CS, Spolski R, Paulos CM, Gattinoni L, Kerstann KW, Palmer DC et al. IL-2 and IL-21 confer opposing differentiation programs to CD8+ T cells for adoptive immunotherapy. Blood 2008; 111: 5326-5333.

38 Sun CM, Hall JA, Blank RB, Bouladoux N, Oukka M, Mora JR et al. Small intestine lamina propria dendritic cells promote de novo generation of Foxp3 $\mathrm{T}$ reg cells via retinoic acid. J Exp Med 2007; 204: 1775-1785.

39 Gomez-Rodriguez J, Sahu N, Handon R, Davidson TS, Anderson SM, Kirby MR et al. Differential expression of interleukin-17A and $-17 \mathrm{~F}$ is coupled to $T$ cell receptor signaling via inducible T cell kinase. Immunity 2009; 31: 587-597.

40 Oldenhove G, Bouladoux N, Wohlfert EA, Hall JA, Chou D, Dos Santos L et al. Decrease of Foxp3+ Treg cell number and acquisition of effector cell phenotype during lethal infection. Immunity 2009; 31: 772-786. 
41 Wange RL, Guitian R, Isakov N, Watts JD, Aebersold R, Samelson LE. Activating and inhibitory mutations in adjacent tyrosines in the kinase domain of ZAP-70. J Biol Chem 1995; 270: 18730-18733.

42 Zhang W, Sloan-Lancaster J, Kitchen J, Trible RP, Samelson LE. LAT: the ZAP-70 tyrosine kinase substrate that links T cell receptor to cellular activation. Cell 998 92, 83-92.

43 Gomez-Rodriguez J, Wohlfert EA, Handon R, Meylan F, Wu JZ, Anderson SM et al. Itk-mediated integration of $\mathrm{T}$ cell receptor and cytokine signaling regulates the balance between Th17 and regulatory T cells. J Exp Med 2014; 211 529-543.
44 Miller SD, Karpus WJ, Davidson TS. Experimental autoimmune encephalomyelitis in the mouse. In John E. Coligan et al. (eds). Current protocols in immunology. Chapter 15: Unit 15 1, 2010.

45 Pepperberg DR, Okajima TL, Ripps H, Chader GJ, Wiggert B. Functional properties of interphotoreceptor retinoid-binding protein. Photochem Photobiol 1991; 54: 1057-1060.

46 Caspi RR Experimental autoimmune uveoretinitis in the rat and mouse. In John E. Coligan et al. (eds). Current protocols in immunology. Chapter 15: Unit 15 6, 2003.

47 Misplon JA, Lo CY, Gabbard JD, Tompkins SM, Epstein SL. Genetic control of immune responses to influenza A matrix 2 protein (M2). Vaccine 2010; 28: 5817-5827.

Supplementary Information accompanies this paper on Gene Therapy website (http://www.nature.com/gt) 